\title{
Engineered T Cell Therapy for Cancer in the Clinic
}

\author{
Lijun Zhao and Yu J. Cao* \\ State Key Laboratory of Chemical Oncogenomics, Key Laboratory of Chemical Genomics, Peking University Shenzhen \\ Graduate School, Shenzhen, China
}

T cells play a key role in cell-mediated immunity, and strategies to genetically modify $\mathrm{T}$ cells, including chimeric antigen receptor (CAR) T cell therapy and T cell receptor (TCR) T cell therapy, have achieved substantial advances in the treatment of malignant tumors. In clinical trials, CAR-T cell and TCR-T cell therapies have produced encouraging clinical outcomes, thereby demonstrating their therapeutic potential in mitigating tumor development. This article summarizes the current applications of CAR-T cell and TCR-T cell therapies in clinical trials worldwide. It is predicted that genetically engineered $\mathrm{T}$ cell immunotherapies will become safe, well-tolerated, and effective therapeutics and bring hope to cancer patients.

Keywords: engineered T cells, CAR-T cell, TCR-T cell, clinic, immunotherapy

\section{OPEN ACCESS}

Edited by:

Weidong Han,

PLA General Hospital, China

Reviewed by:

Pin Wang,

University of Southern California,

United States

Zong Sheng Guo,

University of Pittsburgh School of

Medicine, United States

${ }^{*}$ Correspondence:

Yu J. Cao

joshuacao@pku.edu.cn

Specialty section:

This article was submitted to Cancer Immunity and Immunotherapy,

a section of the journal

Frontiers in Immunology

Received: 10 July 2019 Accepted: 05 September 2019

Published: 11 October 2019

Citation:

Zhao L and Cao YJ (2019) Engineered

$T$ Cell Therapy for Cancer in the Clinic.

Front. Immunol. 10:2250.

do: 10.3389/fimmu.2019.02250

\section{INTRODUCTION}

The microenvironment of solid tumors contains an abundant fibrous matrix and immunosuppressive cells, which can protect the tumor tissue and resist immune cell attack (1). For example, in the pancreatic cancer microenvironment, the content of hyaluronan (HA) increases significantly, which impedes the infiltration of the immune cells (2). Immune checkpoint receptors on tumor cells or immunosuppressive cells can inhibit $\mathrm{T}$ cells, by binding to negative regulatory ligands on $\mathrm{T}$ cells (3). In this low-oxygen, acidic tumor microenvironment (TME) that lack essential amino acids, infiltrating $\mathrm{T}$ cells experience anergy, exhaustion, senescence, and stemness, making it challenging to achieve the desired tumor killing effect (4). There is still no cure for these diseases, and treatments only control their malignant development in various ways. Traditional methods of cancer treatment include surgical resection, radiotherapy and chemotherapy, small molecule targeted drugs, monoclonal antibodies, and hematopoietic stem cell transplantation. Surgical resection is effective for early-stage patients but not for metastatic cancer cells; radiotherapy and chemotherapy are more common but have poor selectivity and produce substantial damage to normal tissues, and targeted drugs (including small molecules and monoclonal antibodies) have better comprehensive efficacy and fewer toxic side effects but can also encourage gene mutation of tumor cells, drug tolerance, and so on (5). Hematopoietic stem cell transplantation is effective; however, choosing a donor is often difficult, and the graft is prone to rejection after the operation. Cellular immunotherapy is at the forefront of cancer therapy (6).

In recent years, great progress has been made in cancer treatment. Researchers not only have a better understanding of various solid and blood cancers but also have expanded the scope and impact of various immunotherapy strategies (7). Immunotherapy is the fastest and most remarkable developing field. Immunotherapy has generated new therapeutic options for a series of solid tumor and blood cancer patients; as such, the 2018 Nobel Prize in Physiology or Medicine was awarded to James P. Allison and Tasuku Honjo, who discovered how to harness the body's 
immune system to fight cancer, highlighting the importance of research progress in the field of immunotherapy (8).

Among immunotherapies, the programmed cell death protein 1 (PD-1) and programmed cell death ligand 1 (PD-L1) checkpoint inhibitors have been shown to be the primary treatment for advanced lung cancer (9-11). Immunotherapy combined with antibody therapy targeting $\mathrm{PD}-1$ or $\mathrm{PD}-\mathrm{L} 1$ (ClinicalTrials.gov number: NCT02366143 and NCT02578680) significantly increased median progression-free survival and 1year overall survival (9-11). On September 30, 2018, the U.S. Food and Drug Administration (FDA) approved a new anti-PD1 checkpoint inhibitor (Cemiplimab; Libtayo) for skin squamous cell carcinoma (Table 1).

A phase III clinical trial (ClinicalTrials.gov number: NCT02231749) has demonstrated that combined immunotherapy can improve the survival rate of renal cell carcinoma. Compared with the use of the tyrosine kinase inhibitor sunitinib, a monoclonal antibody drug, the combination of nivolumab and ipilimumab in the treatment of melanoma, increased the overall survival rate to 18 months in patients with high-risk renal cell carcinoma $(12,13)$. A second-stage study (ClinicalTrials.gov number: NCT02320058) showed that the complete response rate and partial response rate were 26 and $30 \%$, respectively, after treatment with nivolumab and ipilimumab and that $82.8 \%$ of patients were alive 9 months later (14).

In the past 2 years, the most popular chimeric antigen receptor (CAR) $\mathrm{T}$ cell immunotherapy has mainly focused on targeting CD19 in lymphoma. FDA-approved CAR-T cell therapies such as tisagenlecleucel (Kymriah, CTL019) and axicabtagene ciloleucel (Yescarta, KET-C10) (ClinicalTrials.gov number: NCT03123939) have shown long-term benefits $(15,16)$. Anti-CD19 CAR-T cell therapy is a promising option for patients with relapsed and refractory B cell acute lymphoblastic leukemia (15).

Unlike systemic chemotherapy, targeted drug therapies make use of specific gene mutations in cancer cells, unlike systemic chemotherapy. For example, osimertinib, a new epidermal growth factor receptor inhibitor (ClinicalTrials.gov number: NCT01802632), can delay the progression of lung cancer in response to drug resistance mutations (17). Osimertinib has become the preferred initial treatment for some non-smallcell lung cancer patients with epidermal growth factor receptor mutations (18). A targeted therapy for human epidermal growth factor receptor-2 (HER2)/neu mutation, trastuzumab, was developed to treat breast cancer (19). Abemaciclib (Verzenio) is a novel drug (ClinicalTrials.gov number: NCT02102490, NCT02107703, and NCT02246621) that inhibits the activity of the CDK4/6 (cyclin-dependent kinases 4/6) protein, which

TABLE 1 | The FDA has approved a variety of new immunotherapies.

\begin{tabular}{|c|c|c|c|c|}
\hline Trade name & Generic name & Target & Disease & $\begin{array}{l}\text { Approved by } \\
\text { FDA }\end{array}$ \\
\hline Provenge & Sipuleucel-T & PAP & $\begin{array}{l}\text { Asymptomatic or minimally symptomatic metastatic castrate } \\
\text { resistant (hormone refractory) prostate cancer }\end{array}$ & 2010.4 \\
\hline \multirow[t]{2}{*}{ Yervoy } & Ipilimumab & CTLA-4 & Adult patients with inoperable or metastatic melanoma & 2011.3 \\
\hline & & & $\begin{array}{l}\text { Pediatric patients aged } 12 \text { years and older with unresectable or } \\
\text { metastatic melanoma }\end{array}$ & 2017.7 \\
\hline \multirow[t]{3}{*}{ Keytruda } & Pembrolizumab & PD-1 & Advanced or unresectable melanoma & 2014.9 \\
\hline & & & Classic Hodgkin's lymphoma & 2017.3 \\
\hline & & & Recurrent or metastatic cervical cancer & 2018.6 \\
\hline \multirow[t]{2}{*}{ Blincyto } & Blinatumomab & CD19, CD3 & B-cell precursor ALL & 2014.1 \\
\hline & & & MRD positive B cell precursor ALL & 2018.3 \\
\hline \multirow[t]{3}{*}{ Opdivo } & Nivolumab & PD-1 & Advance melanoma & 2014.1 \\
\hline & & & NSCLC & 2015.3 \\
\hline & & & Colorectal cancer & 2017.8 \\
\hline \multirow[t]{2}{*}{ Tecentriq } & Atezolizumab & PD-L1 & NSCLC & 2018.1 \\
\hline & & & First-line treatment for extensive stage small cell lung cancer & 2019.3 \\
\hline \multirow[t]{2}{*}{ Bavencio } & Avelumab & PD-L1 & Metastatic MCC & 2017.3 \\
\hline & & & Locally advanced or metastatic urothelial carcinoma & 2017.5 \\
\hline \multirow[t]{2}{*}{ Imfinzi } & Durvalumab & PD-L1 & Locally advanced or metastatic bladder carcinoma & 2017.5 \\
\hline & & & $\begin{array}{l}\text { Stage } 3 \text { non-small cell lung cancer that is stable after surgery, } \\
\text { chemotherapy, or radiation }\end{array}$ & 2018.2 \\
\hline Kymriah & Tisagenlecleucel & CD19 & B-cell precursor ALL & 2017.8 \\
\hline Yescarta & Axicabtagene Ciloleucel & CD19 & Adults with relapsed or refractory large B-cell lymphoma & 2017.1 \\
\hline Opdivo \& Yervoy & Nivolumab \& Ipilimumab & PD-1, CTLA-4 & Intermediate and poor-risk advanced renal cell carcinoma & 2018.4 \\
\hline Keytruda \& Inlyta & Pembrolizumab \& Axitinib & PD-1, VEGFR & Advanced RCC & 2019.4 \\
\hline
\end{tabular}

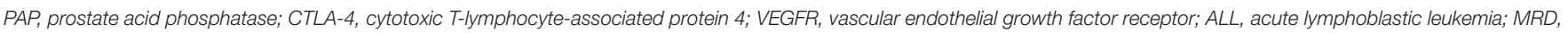
minimal residual lesions; NSCLC, non-small cell lung cancer; MCC, Merkel cell carcinoma; RCC, renal cell carcinoma. 
regulates the cell division rate, rather than targeting specific gene mutations (20-22).

\section{ENGINEERED T CELL THERAPY}

Early adoptive immunotherapy mainly transfuses autologous or allogeneic tumor-responsive T cells back into the patient's body to attack the patient's tumors. This method has been successful $(6,23,24)$. However, this therapy has not been widely used, mainly because of the small number of invasive lymphocytes and the fact that it cannot improve the anti-tumor ability of the body's autoimmune system (6). $\mathrm{T}$ cell genetic engineering therapies can overcome the challenges of low survival and migration of $\mathrm{T}$ cells and immune escape to a certain extent $(25,26)$. $\mathrm{T}$ cells are extracted from the patient's blood and genetically modified to encode receptors that recognize cancer-specific antigens (Figure 1). Additional genes, such as those encoding cytokines, can also be modified to prolong survival and promote $\mathrm{T}$ cell penetration into cancer tissue (26). CAR-T cell therapy and $\mathrm{T}$ cell receptor (TCR)-T cell therapy, as the latest and most effective immunotherapy technologies, have been widely studied in recent years. Clinical research regarding therapies using genetically engineered $\mathrm{T}$ cells has shown remarkable success.

\section{CAR-T CELL THERAPY}

CAR-T cell therapy is a novel tumor immunotherapy technique for cancer treatment (17, 27-29). The efficacy of CAR-T cells for the treatment of acute B lymphocytic leukemia has been widely recognized, and several clinical trials using CAR-T cell therapy in the treatment of various types of tumors have been reported (17, 27-29). This approach is also more specific and more customizable because the antigen-binding domain can be changed to target various tumor targets (17, 27-29). Moreover, CAR-T cells can also establish memory in patients with advanced leukemia (30).

A CAR is the core component of CAR-T cells, making T cells MHC unrestricted. This phenomenon enables the modified $\mathrm{T}$ cells to recognize more extensive targets than the natural TCR on $\mathrm{T}$ cell surface and is not restricted by major histocompatibility complex (MHC) molecules. A CAR is a recombinant receptor with both tumor-antigen-binding and $\mathrm{T}$ cell-activating functions (Figure 2) $(31,32)$. The extracellular domain is a single-chain variable antibody domain $(\mathrm{scFv})$, which can recognize specific antigens of tumors (25). The heavy-chain variable region $(\mathrm{VH})$ and light-chain variable region (VL) of antibodies are linked by a small segment of polypeptide. Via the scFv, CAR-T cells can directly recognize and bind to tumor-specific antigens $(25,33)$. The hinge domain is composed of immunoglobulin superfamily members, such as $\mathrm{CD} 8, \mathrm{CD} 28$, or IgG, which play a role in signal transduction (25). The intracellular signal transduction region is mainly composed of the $\mathrm{CD} 3 \zeta$ chain of the TCR (25). In addition to intracellular signaling domains, costimulatory molecules such as CD28 or 4-1BB (CD137) can improve cell proliferation and survival time in vivo and enhance the anti-tumor activity of CAR$\mathrm{T}$ cells $(25,34)$. CAR-T cells directly recognize tumor surface antigens, and are not restricted by MHC class. When CAR-T cells bind to tumor surface antigen, they proliferate and kill tumor cells.

The activation of $\mathrm{T}$ cells mediated by first-generation CARs is accomplished through the tyrosine activation motif on the $\mathrm{CD} 3 \zeta$ chain (Figure 2) or $\mathrm{FcR} \gamma(25,35,36)$. The $\mathrm{CD} 3 \zeta$ chain can provide signals for $\mathrm{T}$ cell activation and target cell lysis, regulation of IL-2 secretion, and anti-tumor activity in vivo (36). However, the anti-tumor activity of first-generation CARmodified $\mathrm{T}$ cells is limited in vivo, and this decreased $\mathrm{T}$ cell proliferation ultimately leads to $\mathrm{T}$ cell apoptosis $(35,36)$. Secondgeneration CARs incorporate an additional costimulatory signal. Experiments show that this signal amplifies the original "signal 1" derived from the TCR/CD3 complex and increases T cell proliferation and cytokine secretion, promoting the secretion of anti-apoptotic proteins (37). A commonly used costimulatory molecule is CD28 or CD137(4-1BB). To further improve the design of CARs, many research groups have focused on the development of third-generation CARs, which include not only $\mathrm{CD} 3 \zeta$ and one costimulatory domain but also an additional costimulatory signal (34). Based on these second or thirdgeneration CARs, fourth-generations CAR- T cells coexpress some key cytokines or costimulatory ligands, such as IL-12, IL15 , and IL-7, or suicide genes, which significantly enhance the expansion activity of $\mathrm{T}$ cells. For fifth generation CAR-T cells, it has been proposed to knock out the human leukocyte antigen (HLA) and TCR genes of T cells obtained from healthy donors to avoid host immune rejection or graft-vs.-host disease against transplanted CAR-T cells $(3,18,38)$. Because it does not need to be modified according to the patient, this strategy can be used for the treatment of multiple patients (18).

Different researchers have used different targets and costimulatory signals to compare the results of secondgeneration and third-generation CARs. Some studies have reported that recombinant $\mathrm{T}$ cells expressing third-generation CARs have significantly increased anti-tumor activity, survival, and cytokine release abilities (34). It is worth noting that the above differences are conclusions obtained from only ex vivo mice experiments, and there are no in vivo comparisons of second-generation and third-generation CARs. The difference between the two generations of CARs may originate not only from the signal transduction domain but also from the extracellular antigen-binding domain $(\mathrm{scFv})$, the transfection method used for the recombinant $\mathrm{T}$ cells (Lentivirus vs. Retrovirus), and the transfusion mode of recombinant $\mathrm{T}$ cells (intravenous transfusion vs. peritoneal infusion vs. intratumor infusion).

\section{CAR-T Cell Therapy Process}

CAR-T cell therapy is a revolutionary targeted immunotherapy $(17,27-29)$. It necessitates modification of patient $\mathrm{T}$ cells outside the body and retransfusion of these cells back into the human body to fight the target cancer cells. The typical CAR-T cell production process is divided into five steps (Figure 1) (25). The first step is to isolate $\mathrm{T}$ cells from cancer patients. The second step is to modify the $\mathrm{T}$ cells with CARs so that the $\mathrm{T}$ cells can simultaneously recognize tumor cells and activate 


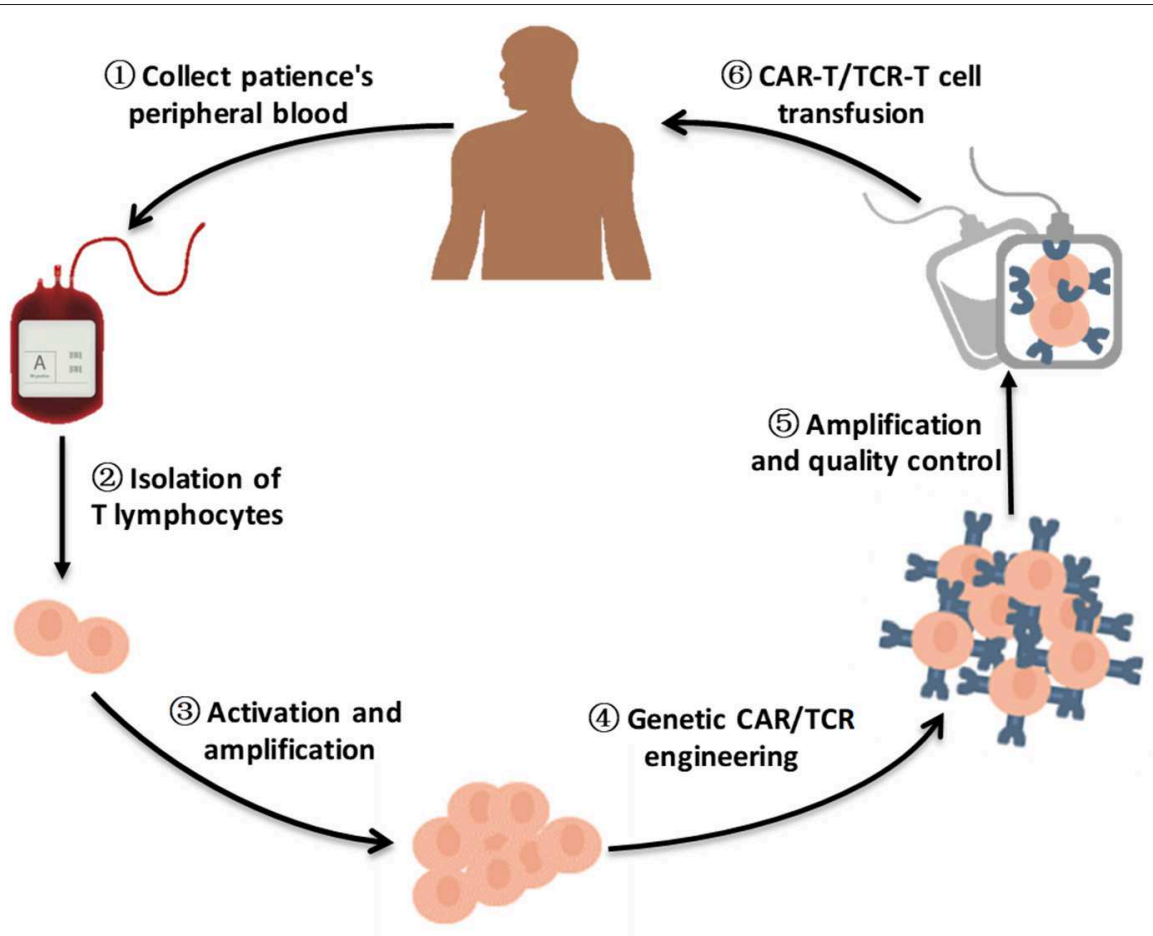

FIGURE 1 | A brief flow chart of engineered-T cell therapy. A sufficient amount of blood is drawn from patients to obtain enough peripheral blood mononeuclear cells (PBMCs) for engineered T cell manufacturing. The T cells are purified from patients PBMCs. After activation and amplification in vitro, T cells are modified by viral vector transfection, such as lentivirus transfection or retrovirus transfection, to express specific CARs/TCRs on the T cell surface. Following amplification and quality control, CAR-T cells/TCR-T cells are infused into the patient body to improve antitumor ability.

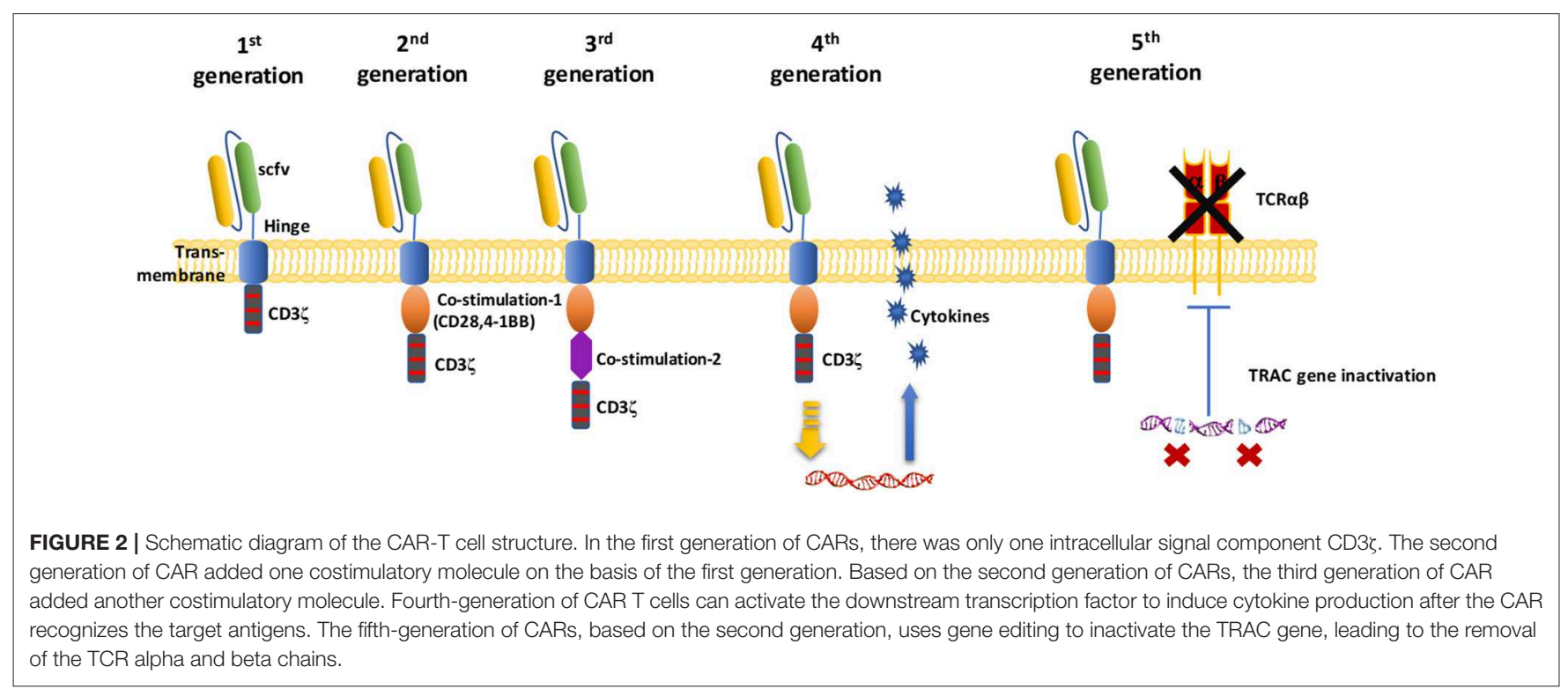

T cells, creating CAR-T cells $(6,25)$. In the third step, CAR$\mathrm{T}$ cells are cultured ex vivo and stimulated by cytokines to produce a large number of CAR-T cells (25). The fourth step is to transfuse the expanded CAR-T cells back into the patient at an appropriate dose (25). Finally, patients need to be closely monitored, especially to monitor and control severe physical reactions in the following few days (6). The whole process lasts approximately 3 weeks, and the preparation of CAR-T cells requires approximately 2 weeks, making the cell preparation step the most time-consuming step (25).

CAR-T cells are expanded ex vivo and frozen for future administration. Patients are given preconditioning 
chemotherapy (6). Following tumor burden reassessment, CAR-T cells are infused. When the antigen-binding domain recognizes malignant antigen, it stimulates the downstream activation signal and produces specific killing effects. The use of such CAR-T cell therapies in B cell lymphoma/leukemia in the clinic has achieved complete remission in a number of relapsed and refractory advanced patients (15).

\section{Recruited Patients}

To lay a foundation for the application of CAR-T cell therapy, clinical trials recruit suitable patients, and they must satisfy certain conditions. Patients aged older than 75 years or younger than 1 year will be detrimental to clinical trials, and the survival time should be at least 3 or 6 months. The recruited patients are usually relapsed or refractory, or they have experienced chemotherapy failure, bone marrow transplantation failure, or autologous, allogeneic hemopoietic stem cell transplantation failure, or have been unable to find an effective treatment. Although patients are widely recruited, some patients are excluded, such as those who have clinically significant cardiovascular disease or those who are pregnant or lactating. Patients who have participated in any other clinical trials in the past 30 days are excluded. Additionally, patients with any type of primary immunodeficiency are excluded from the clinical studies. Other symptoms are not applicable for CAR-T cell therapy because they may increase patient risk or interfere with clinical test results. The main goal of trials is to evaluate the safety, effectiveness, and feasibility of CAR-T cell immunotherapy.

\section{Pretreatment of the Patient}

In addition to killing cancer cells directly, the use of some chemotherapeutic drugs, such as fludarabine (FA) and cyclophosphamide (CTX), as pretreatment regimens before immunotherapy, may produce synergistic immunobiological effects, thereby enhancing the effects of anti-tumor immunotherapy (39). Pretreatment chemotherapy can remove existing lymphocytes in lymphoid tissue or bone marrow tissue, establish implantation space for newly implanted antitumor immune cells, and induce the production of bone marrow cytokines, thus promoting the recovery and proliferation of immune cells $(28,40)$. CTX is the most commonly used drug for pretreatment in cancer immunotherapy. In addition, other commonly used pretreatment chemotherapy drugs include FA, gemcitabine (GEM), lenalidomide, and docetaxel (DTX). For example, when FR $\alpha$ (Folate receptor $\alpha$ ) CAR-T cells were used to treat patients with end-stage ovarian cancer, the pretreatment regimen was CTX $300 \mathrm{mg} / \mathrm{m}^{2} /$ day for three consecutive days and FA $30 \mathrm{mg} / \mathrm{m}^{2} /$ day for three consecutive days (41). For melanoma patients, Deniger et al. of the National Cancer Institute (NCI) formulated a routine regimen of $60 \mathrm{mg} / \mathrm{kg} /$ day CTX for 2 days and $25 \mathrm{mg} / \mathrm{m}^{2} /$ day FA for 5 days (42). However, the dosage, mode, and sequence of pretreatment still need further optimization and verification by more clinical trials.

\section{Injection Dose}

In clinical treatment, CAR-T cells are injected at a wide range of doses, sometimes with dose-increasing regimens. Some reports suggest that there is a correlation between the dose of CAR-T cells injected and the incidence and severity of the cytokine release storms (CRS) (43). The total number of CAR-T cells ranges from $1 \times 10^{5} / \mathrm{kg}$ to $1 \times 10^{10} / \mathrm{kg}$ CAR-T cells or more. Sometimes, to investigate the patient's tolerance, the total number of cells is injected over three courses, $10 \%$ on the first day, $30 \%$ on the second day, and $60 \%$ on the third day (44). One patient with chronic lymphoblastic leukemia who was treated with CAR-T cell therapy has been cancer free for 5 years (45). More importantly, that study found that the minimum cell number required for CAR-T cell therapy to exert its anticancer effects was only one cell (45).

\section{Success and Advantages of CAR-T Cell Therapy}

Emily Whitehead was the first pediatric ALL patient to receive CAR-T cell treatment. The University of Pennsylvania CAR-T cell clinical trial completely cured Emily's leukemia, and Emily has become a spokesperson for CAR-T cells. Here, we present three recent successful cases to illustrate the potential of CAR-T cell immunotherapy in cancer treatment. In a clinical trial for children and young adults with cancer, none of whom had responses to standard therapy, a CAR-T cell therapy called tisagenlecleucel (Kymriah) was successful in 52 of 63 patients. In the study, three out of every four patients did not relapse after 6 months (46). According to the results of this study, FDA approved tisagenlecleucel in August 2017 for the treatment of relapsed or refractory B-cell precursor ALL in patients $\leq 25$ years old.

Another study used CAR-T cell therapy to treat refractory large B-cell lymphoma. The CAR-T cell therapy used in this study is called axicabtagene ciloleucel (Yescarta) (28). Immunotherapy slowed or stopped the growth of cancer in $82 \%$ of patients, and more than half $(54 \%)$ of the cancers disappeared completely (28). Nearly 15.4 months later, approximately $40 \%$ of patients still showed no signs of cancer. In October 2017, the FDA approved axicabtagene ciloleucel for the treatment of adults with relapsed or refractory large B-cell lymphoma, including diffuse large B-cell lymphoma (DLBCL), after two or more lines of systemic therapy.

Multiple myeloma is an incurable disease, and only approximately half of patients are still alive 5 years after diagnosis. Early clinical trials presented at the 2017 American Society of Clinical Oncology (ASCO) annual meeting showed that CAR-T cell therapy using B cell maturation antigen (BCMA) as a biomarker could prevent the development of multiple myeloma. The study included 35 patients with multiple myeloma who relapsed after treatment or were resistant to treatment. Of these 35 patients, $74 \%$ experienced a complete response of multiple myeloma after receiving BCMA CAR-T cells (47).

CAR-T cells are not restricted by MHC molecules. They specifically recognize antigens and kill tumor cells more effectively. Tumor infiltrating lymphocytes (TILs) and TCRs can recognize only the antigens presented by specific MHC molecules and tumors may escape immune surveillance due to 
downregulation or mutation of MHC molecules in tumor cells, resulting in clinical limitations (47).

\section{Failures and Challenges of CAR-T Cell Therapy}

The first third-generation CAR-T cell clinical studies included HER2-targeted CAR-T cell therapy and indications for metastatic melanoma. The NCI chose to make use of an scFv targeting HER2 in a CAR-T cell for therapy for HER2+ melanoma (48). The first patient received a high concentration of CAR-T cells, with a total dose of $1 \times 10^{11}$ cells. After treatment, the patient experienced extreme pain within a few minutes and soon fell into a coma. Doctors administered a high-dose hormone intervention, and the patient died 5 days later. Subsequently, CAR-T cells were found throughout the patient's body, and the lungs were the most seriously infiltrated organ. Further analysis may find that HER2 expression in pulmonary epithelial cells was the main cause of this fatal lung $\mathrm{T}$ cell infiltration (48).

Some types of immunotherapy can attack cancer or slow its spread to other parts of the body. Others make it easier for the immune system to destroy cancer cells, but immunotherapy sometimes leads to the immune system attacking healthy cells, resulting in side effects. Different types of immunotherapy can cause different side effects. The occurrence of many side effects depends on the type of treatment, the type and location of the cancer, and the patient's overall health. Skin redness, blistering, and dryness are common reactions associated with immunotherapy. Fatigue, fever, chills, weakness, nausea, vomiting, dizziness, body pain, and hypertension or hypotension are also side effects of immunotherapy. This new approach to cancer treatment is powerful, and serious risks need to be considered before starting treatment. In particular, there are always possible side effects of treatment, including CRS and neurological problems.

\section{CRS}

CRS is caused by the production of a large number of inflammatory molecules by CAR-T cells. CRS can cause longterm fever, hypotension, dyspnea, and organ problems. Severe CRS can be a life-threatening problem, requiring intensive medical care, including the use of ventilators, drugs to increase blood pressure, and antiepilepsy drugs. The FDA approved intravenous injection of tocilizumab (Actemra), an IL-6 receptor inhibitor, for the treatment of CAR-T cell-induced severe or life-threatening CRS in patients 2 years of age and older. CRS is the most frequently mentioned adverse reaction in CAR$\mathrm{T}$ cell treatment. After infusion of CAR-T cells, a systemic inflammatory reaction caused by a rapid rise in cytokines such as IL-1 and IL-6 was observed in a mouse model $(49,50)$. CRS usually occurs within 2 days after CAR-T cell infusion, and the worst part of the reaction occurs within 1-2 weeks after CAR-T cell infusion (51). It is worth noting that in the pathophysiological process of CRS, not only activated CAR$\mathrm{T}$ cells but also monocytes, macrophages, and dendritic cells participate in the synthesis and release of cytokines, which leads to the corresponding clinical symptoms (50). Studies have shown that patients with massive lesions, patients with a high tumor burden, patients with complications, and patients with CRS after 3 days of CAR-T cell infusion are prone to severe CRS (50). Therefore, treatment evaluation before CAR$\mathrm{T}$ cell infusion is of great significance for CRS control and prognostication. For tocilizumab, a dosage of 4 to $8 \mathrm{mg} / \mathrm{kg}$ should be infused intravenously (51). It should be noted that tocilizumab cannot effectively improve the neurotoxicity of CRS due to the blood-brain barrier (50). Methylprednisolone has been used in patients with severe CRS who did not receive tocilizumab.

\section{Neurotoxicity}

The overall incidence of neurotoxicity is $40 \%$ (52). The most common symptoms include decreased consciousness, confusion, seizures, and brain edema. Neurotoxicity can occur alone or simultaneously with CRS (31). Mild clinical signs can spontaneously regress within a few days. Severe symptoms may require treatment with single agents or combination with dexamethasone (10 mg intravenously or orally) $(51,53)$. Strategies to reduce CRS and neurotoxicity fall into two categories: preventive strategies aimed at reducing the occurrence of severe toxicity and remedial strategies aimed at minimizing toxicity once lethal toxicity occurs. Preventive strategies include reducing the burden of cancer by chemotherapy and reducing the dose of CAR-T cells in patients with high cancer burden before receiving CAR-T cell infusion (52). Without affecting the treatment of CAR-T cells, early intervention with tocilizumab and dexamethasone seems to reduce the incidence of severe CRS (51).

\section{On-Target-Off-Tumor Toxicity}

The ideal target antigen is tumor-specific and expressed only on the surface of cancer cells. Unfortunately, most of the antigens expressed in tumors are not specific to tumors; For example, most CARs target tumor-associated antigens, but this often leads to the possibility of mistargeting. Additionally, attention should be paid to the selection of secretory antigens to avoid the possibility of mistargeting by CAR-T cells. As long as the target is not $100 \%$ tumor-specific, there will be an off-target effect, which is the main source of CAR-T cell side effects. This means that these targets are expressed not only in cancer tissues but also in normal tissue (52). Specific antigens expressed only on the surface of cancer cells can be selected, or multiple antigen complex CAR structures can be designed to identify antigens. The best example of remedial strategies is the addition of suicide or elimination genes to CAR$\mathrm{T}$ cells, which can be activated to selectively deplete CAR-T cells in the event of severe toxicity (54). Thus, "on-target-off-tumor" toxicity can be efficiently avoided.

\section{Exhaustion of CAR-T Cells}

Because of $\mathrm{T}$ cell exhaustion, $\mathrm{T}$ cells entering solid tumors may stop working. Coexpression of some cytokines, such as IL-15, promotes $\mathrm{T}$ cell proliferation and persistence in a mouse model (55). The Nr4a (nuclear receptor transcription factors) family of transcription factors plays a prominent role in regulating genes related to $\mathrm{T}$ cell exhaustion (56). Scientists have used melanoma mouse models to demonstrate that treatment with 
CAR-T cells lacking these Nr4a transcription factors can reduce tumor sizes and improve survival in mice (57). These results suggest that the nuclear factor of activated T cells (NFAT) and Nr4a proteins are helpful in resisting $\mathrm{T}$ cell exhaustion in cancer and are "exhaustion markers" of T cells in a mouse model (57). However, the results of this experiment cannot be used in clinical practice because the consequences of editing multiple genes in human cells are unknown. Understanding the roles of $\mathrm{Nr} 4 \mathrm{a}$ transcription factors provides cancer researchers with new targets for designing better therapies. The molecular design of CARs also has a significant effect on the proliferation and persistence of CAR-T cells. A CAR carrying the inducible costimulatory molecule (ICOS) costimulatory domain (ICOS-CAR) shows an improved ability to maintain the persistence of CD4+ T cells in a mouse model costimulatory (58). By injecting a mixture of CD4+ and CD8+ T cells expressing different CARs into mice at a ratio of $1: 1$, researchers found that CD4+ T cells expressing an ICOSCAR not only increased their own persistence but also increased the persistence of the CD8 $+\mathrm{T}$ cells (58). The anticancer effect of this cell combination was also strongest in mice with non-smallcell lung cancer. When ICOS and 4-1BB costimulatory domains were added to the intracellular costimulatory domain of a thirdgeneration CAR-T cell (ICOSBBz-CAR-T cell), and both CD4+ and CD8+ T cells expressed this ICOSBBz-CAR, the resulting $\mathrm{T}$ cells not only had better persistence but also had a better anticancer effect than a combination of CD4+ T cells expressing ICOS-CAR and CD8+ T cells expressing BBz-CAR (58). The expression level of ICOSBBz-CAR on the T cell surface was lower than that of ICOS-CAR or BBz-CAR. A possible reason for this finding is that the expression of the CAR was too high, which can cause $\mathrm{T}$ cells to be continuously activated, leading to their early depletion.

\section{Tumor Escape}

Although the patient response rate to CAR-T cells is very high, many patients treated with CAR-T cells will have disease recurrence. There are many reasons for this recurrence, such as antigen downregulation on tumor cells or low antigen levels. The mechanism of cancer evasion is closely related to the TME. The TME can influence the heterogeneity of tumors and play a key role in the subsequent development and metastasis of tumors (59). Mechanisms of immune escape include alterated of the expression of G1 regulatory proteins; production of inhibitors such as IL-10, transforming growth factor-beta (TGF- $\beta$ ), and indoleamine 2,3-dioxygenase (IDO); overexpression of immunosuppressive receptors such as PD-L1; and recruitment of Tregs (60). Therefore, combination therapies with immunological checkpoint inhibitors (such as a PD-1/PDL1 antibody) should be adopted.

\section{Treatment for Solid Tumors}

The unprecedented success of CAR-T cell therapy in the treatment of hematological tumors has inspired people to extend this technology to solid tumors. Increasing numbers of clinical trials using CAR-T cell therapy for solid tumors have been carried out. However, the results of clinical trials are often unsatisfactory. The therapeutic effect of CAR-T cell therapy for solid tumors is greatly inferior to that of CAR$\mathrm{T}$ therapy for hematological tumors and is often accompanied by toxicities (61). Hematological tumor cells are dispersed, and solid tumors usually form solid masses in certain organs early in the cancer process, which not only causes many obstacles for the recruitment of immune cells to the affected area but also results in the accumulation of many kinds of immunosuppressive cells and molecules (60). The antigens of hematological tumors are often specific and not expressed in other normal tissues, while the antigens of solid tumors are generally expressed in small amounts in other locations, such as the heart, lung, and liver, leading to mistargeted effects after treatment.

\section{Encephaledema}

In May 2016, one patient treated with JCAR015 died of cerebral edema, and two died of the same symptoms in July, so the experiment was suspended (61). Juno's researchers explained that the pretreatment scheme used CTX and FA and reported that FA would be eliminated from the pretreatment regimen in the subsequent attempt. Two more patients died of brain edema after the trial was restarted, and the trial was suspended again (61). In fact, the problem was not FA. It may have occurred because the costimulatory signal of CD28 is too strong, resulting in immune side effects and leading to brain edema. While 4$1 \mathrm{BB}$ is not as strong as CD28 as a costimulatory molecule, it provides late-acting signals to regulate $\mathrm{T}$ cell poliferation and survival (62). In the late stage of the immune response, $\mathrm{T}$ cells express inhibitory receptors such as CTLA-4, while CD28 expression is downregulated, leading to $\mathrm{T}$ cell loss of the second activation signal of the CD28-B7 pathway. However, 4-1BB is still expressed in the late stage of the $\mathrm{T}$ cell response, indicating that it persists longer.

\section{The Cost of CAR-T Cell Therapy}

The two available CAR-T cell therapies are currently very expensive. Novartis's CAR-T cell therapy, Kymriah, costs an average of $\sim \$ 510,963$, and Yescarta costs an average of approximately $\$ 402,647(63,64)$. If the patient does not experience an effect after CAR-T treatment for 1 month, the medical expenses can be waived. It takes approximately half a month to 1 month to make a specific CAR-T cell product for use in patients. Many enterprises are now studying more efficient and stable production strategies for CAR-T cells. For example, ThermoGenesis, a U.S. automation equipment company, has developed a platform called CAR-TXpress ${ }^{\mathrm{TM}}$ that specializes in producing CAR-T cells. The production cost of CAR-T cells can be greatly reduced. CAR-T cells are produced faster, and the quality of the cells is better. Thus, companies not only can use higher-quality cells for clinical research, allowing faster development of CAR-T cell therapies for more diseases, but also can achieve faster commercialization, making CAR-T cell therapies more readily available on the market (65). Because the cost of CAR-T cell immunotherapy is very high, many patients with leukemia who cannot afford such therapies are excluded from treatment, but with the development of this production strategy and the implementation of a series of national medical 
TABLE 2 | Current clinical targets of CAR-T therapy for hematological malignancies (ClinicalTrials.gov).

\begin{tabular}{|c|c|c|c|c|c|}
\hline Target & Disease & Stage & Phase & NCT number & Country \\
\hline \multirow[t]{7}{*}{ CD19 } & Refractory CD19+ lymphoma and leukemia & Completed & 1 & NCT01626495 & United States \\
\hline & B-cell leukemia or lymphoma & & 1 & NCT01029366 & United States \\
\hline & Refractory B cell malignancy & & $|/| \mid$ & NCT02132624 & Sweden \\
\hline & B cell leukemia or lymphoma & & I & NCT01593696 & United States \\
\hline & ALL & & 1 & NCT01551043 & United States \\
\hline & Resistant or refractory CD19+ ALL & & 1 & NCT02975687 & China \\
\hline & Resistant or refractory CD19+ ALL & & $\|$ & NCT02030847 & United States \\
\hline \multirow{9}{*}{$\begin{array}{l}\text { CD19 } \\
+ \text { CD22 }\end{array}$} & Relapsed or refractory lymphoma and leukemia & Recruiting & $|/| \mid$ & NCT03398967 & China \\
\hline & CD19 positive diffuse large B-cell lymphoma or B ALL & & I & NCT03233854 & United States \\
\hline & CD19+CD22+ leukemia & & I & NCT03330691 & United States \\
\hline & Refractory and/or Recurrent B cell malignancies & & $|/| \mid$ & NCT03098355 & China \\
\hline & Children or young adults with CD19 positive B ALL & & 1 & NCT03241940 & United States \\
\hline & B-cell ALL & & $|/| \mid$ & NCT03614858 & China \\
\hline & B-cell ALL & & $|/| \mid$ & NCT03289455 & United Kingdom \\
\hline & B-cell hematologic malignancy & & $|/| \mid$ & NCT02903810 & China \\
\hline & CD19/CD22-expressing B cell malignancies & & 1 & NCT03448393 & United States \\
\hline CD19+ CD20 & Relapsed or refractory lymphoma and leukemia & Recruiting & $|/| \mid$ & NCT03398967 & China \\
\hline \multirow[t]{6}{*}{ CD22 } & CD22+ leukemia and lymphoma & Active & 1 & NCT03244306 & United States \\
\hline & Chemotherapy resistant or refractory ALL & Terminated & 1 & NCT02588456 & United States \\
\hline & B cell malignancies & Recruiting & $|/| \mid$ & NCT02935153 & China \\
\hline & B cell malignancies & Recruiting & $\mid / I I$ & NCT03262298 & China \\
\hline & ALL & Recruiting & 1 & NCT03620058 & United States \\
\hline & ALL & Recruiting & 1 & NCT02650414 & United States \\
\hline \multirow[t]{3}{*}{ CD20 } & Refractory or relapsed B lymphocyte lymphoma & Recruiting & 1 & NCT03576807 & China \\
\hline & B cell malignancies & Recruiting & $|/| \mid$ & NCT02710149 & China \\
\hline & Relapsed or refractory B cell non-Hodgkin lymphomas & Recruiting & $|/| \mid$ & NCT03277729 & United States \\
\hline \multirow[t]{2}{*}{ ROR1R } & ROR1+ malignancies & Recruiting & 1 & NCT02706392 & United States \\
\hline & CLL & Withdrawn & I & NCT02194374 & United States \\
\hline CD4 & CD4+ lymphoma and leukemia & Recruiting & 1 & NCT03829540 & United States \\
\hline CD7 & High risk $T$ cell malignancies & NR & I & NCT03690011 & United States \\
\hline CD38 & Relapsed B-cell ALL after anti-CD19 CAR-T therapy & Recruiting & $|/| \mid$ & NCT03754764 & China \\
\hline \multirow[t]{2}{*}{ CD30 } & Lymphocyte malignancies & Recruiting & $|/| \mid$ & NCT02958410 & China \\
\hline & Hodgkin lymphoma, adult & NA & - & NCT03914885 & United States \\
\hline \multirow[t]{2}{*}{ BCMA } & High-risk multiple myeloma & Recruiting & $\mid / I I$ & NCT03455972 & China \\
\hline & B-cell lymphoma and leukemia & Recruiting & $|/| \mid$ & NCT02954445 & China \\
\hline
\end{tabular}

CLL, chronic lymphocytic leukemia; ROR1R, receptor tyrosine kinase-like orphan receptor; NA, not available; NR, not yet recruiting.

policies, it is believed that an increasing number of patients will benefit from this therapy.

\section{Current Clinical Target of CAR-T Cell Therapy in Hematological Malignancies}

The expression of $\mathrm{CD}$ molecules as surface markers can be used for the identification of cell types. Several clinical studies using CD19 as the target of CAR-T cells have been registered. In addition to CD19, which is the most widely reported target, there are many tumor-related targets that have entered phase I and phase II clinical trails. In currently registered clinical trials and published research results, $B$ cell maturation antigen (BCMA) has been presented as a particularly important target. At present, there are many targets involved in clinical CAR-T cell projects.
Current clinical trials of CAR-T cell therapies mainly focus on CD19, CD20, CD22, GPC3 (Glypican-3), BCMA, and other promising targets (Table 2 and Figure 3).

As of May 2018, 19 clinical applications for CAR-T cell projects from 13 enterprises had been accepted by the CDE (Drug evaluation center of state drug administration) in China; most of these applications targeted CD19. The clinical application of the LCAR-B38M CAR-T cell preparation submitted by Nanjing Legend was formally accepted by the CDE, and it became the first CAR-T cell product to be clinically accepted in China. This product is a BCMA-targeted CAR-T cell product that is mainly used for relapsed or refractory multiple myeloma. A total of 57 patients with multiple myeloma from the Second Affiliated Hospital of Xi'an Jiaotong University 
Current clinical target of CAR-T therapy in hematological malignancies

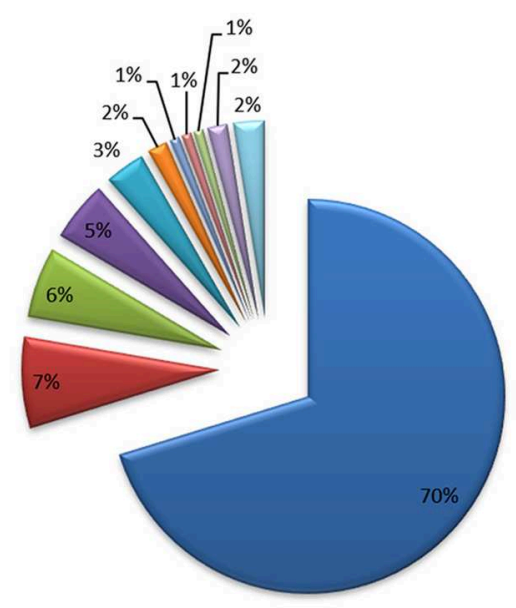

GD19

曰 $\mathrm{CD} 19+\mathrm{CD} 22$

$\square \mathrm{CD} 19+\mathrm{CD} 20$

由 CD22

$\square \mathrm{CD} 20$

口OR1R

$\square \mathrm{CD} 4$

$\square \mathrm{CD} 7$

$\triangle \mathrm{CD} 38$

$\square \mathrm{CD} 30$

$\square \mathrm{BCMA}$

FIGURE 3 | Current clinical targets for CAR-T treatment of hematologic malignancies. The pie chart is based on the statistical result of CAR-T clinical trials for hematologic malignancies registered on ClinicalTrials.gov.

participated in the LCAR-B38M clinical trial (66). The overall response rate was $88 \%$, and $68 \%$ of patients achieved a complete response.

The Department of Hematology, Jiangsu Institute of Hematology, China, conducted the first clinical study to treat relapsed/refractory acute lymphoblastic leukemia by sequential transfusion of two types of CAR-T cells: CD19CAR-T cells and CD22-CAR-T cells (67). Infusion of mixed second-generation CAR-T cells is feasible and safe for patients with refractory/recurrent ALL. Combination therapy against multiple target antigens should be an effective way to overcome recurrence after antigen escape.

\section{Current Clinical Targets of CAR-T Cell Therapy in Solid Tumors}

Because of their relatively isolated physiological locations and special immunosuppressive microenvironments, immunotherapy is less effective for solid tumors than for hematological tumors (Table 3 and Figure 4) (68). Regulating the level of chemical flooding factors on the surface of $\mathrm{T}$ cells can encourage these cells to enter solid tumors. The immunosuppressive microenvironment of solid tumors is mainly caused by cytokines such as IL-6 and TGF-beta and immunosuppressive cells such as Tregs and myeloid-derived suppressor cells (MDSCs). The use of neutraling (blocking) antibodies against these cytokines and immunosuppressive cells can reverse the immunosuppressive microenvironment to some extent (69). Moreover, the use of nonspecific PD-1 and CTLA-4 antibodies to reverse $\mathrm{T}$ cell inhibition can also resolve the poor efficacy of $\mathrm{T}$ cell immunotherapy for solid tumors to a certain extent $(68,69)$.

\section{Published Clinical Targets of CAR-T Cell Therapy in Hematological Malignancies}

CAR- $T$ cell immunotherapy has been proven to be a breakthrough in the treatment of hematological tumors, showing good targeting, lethality, and persistence (Table 4). The two CAR-T cell products $(17,29)$ approved by Novartis and Kite Pharma are suitable for acute lymphoblastic leukemia and $\mathrm{B}$ cell lymphoma, respectively, and their application is being investigated in blood cancers $(17,29)$. The application of CAR-T cell therapy in solid tumors has been relatively slow. Statistics show that approximately $75 \%$ of CAR-T cell clinical trials in the world are used for leukemia, lymphoma, and other blood cancers, and only a small number of CAR-T cell projects target solid tumors such as liver cancer and lung cancer.

The FDA announced approval of Kite Pharma's CAR-T cell therapy Yescarta for adult patients with specific types of large B cell lymphoma in October 2017. These patients had received at least two other treatments, but no remissions occurred. It is worth mentioning that this is the first non-Hodgkin lymphoma-specific CAR-T cell therapy approved by the FDA $(17,29)$ and the second approved CAR-T cell therapy. In a multicenter clinical trial, more than 100 adult patients were treated with Yescarta and showed surprising results: complete remissions (CRs) with Yescarta was observed in $51 \%$ of patients.

Researchers from the University of Texas M.D. Anderson Cancer Center in Houston conducted a CAR-T cell study involving 111 patients who had a specific type of B cell lymphoma and relapsed after other treatments. In this study, the researchers collected T cells from patients, genetically modified them under laboratory conditions to target lymphoma cells, and eventually transfused them back into the patients after amplification. After a median follow-up of 15.4 months, $42 \%$ of patients continued to have a response and $40 \%$ of patients had a complete response (28). As expected, 13\% had grade 3 or higher CRS, which led to fever, and $28 \%$ had neurological disorders, among other adverse reactions (ClinicalTrials.gov number: NCT02348216).

A new CAR-T cell therapy targeting the surface molecule CD22 has been designed. A phase I trial of this CAR-T cell platform recruited 21 children and young adults (aged 7-30) with B-ALL who had relapsed or had not responded to previous treatments (79). Fifteen of these patients also received CAR-T cell therapy targeting CD19, but no significant improvements were achieved. These patients were given different doses of the CD22-targeting CAR-T cell therapy. A total of $73 \%$ patients achieved complete remission after receiving $\geq 1 \times 10^{6} \mathrm{CD} 22$ CAR-T cells (79).

\section{Published Clinical Targets of CAR-T Cell Therapy in Solid Tumors}

There are many reasons for the remarkable progress of CAR-T cell therapy in hematological tumors and the slow progress in solid tumors (82). On the one hand, there are major differences between solid tumors and hematological tumors. The high heterogeneity makes treatment of solid tumors with CAR-T cell therapy much more difficult. Additionally, tumor antigens associated with solid tumors are expressed not only in tumor 
TABLE 3 | Current clinical targets of CAR-T therapy for solid tumors (ClinicalTrials.gov).

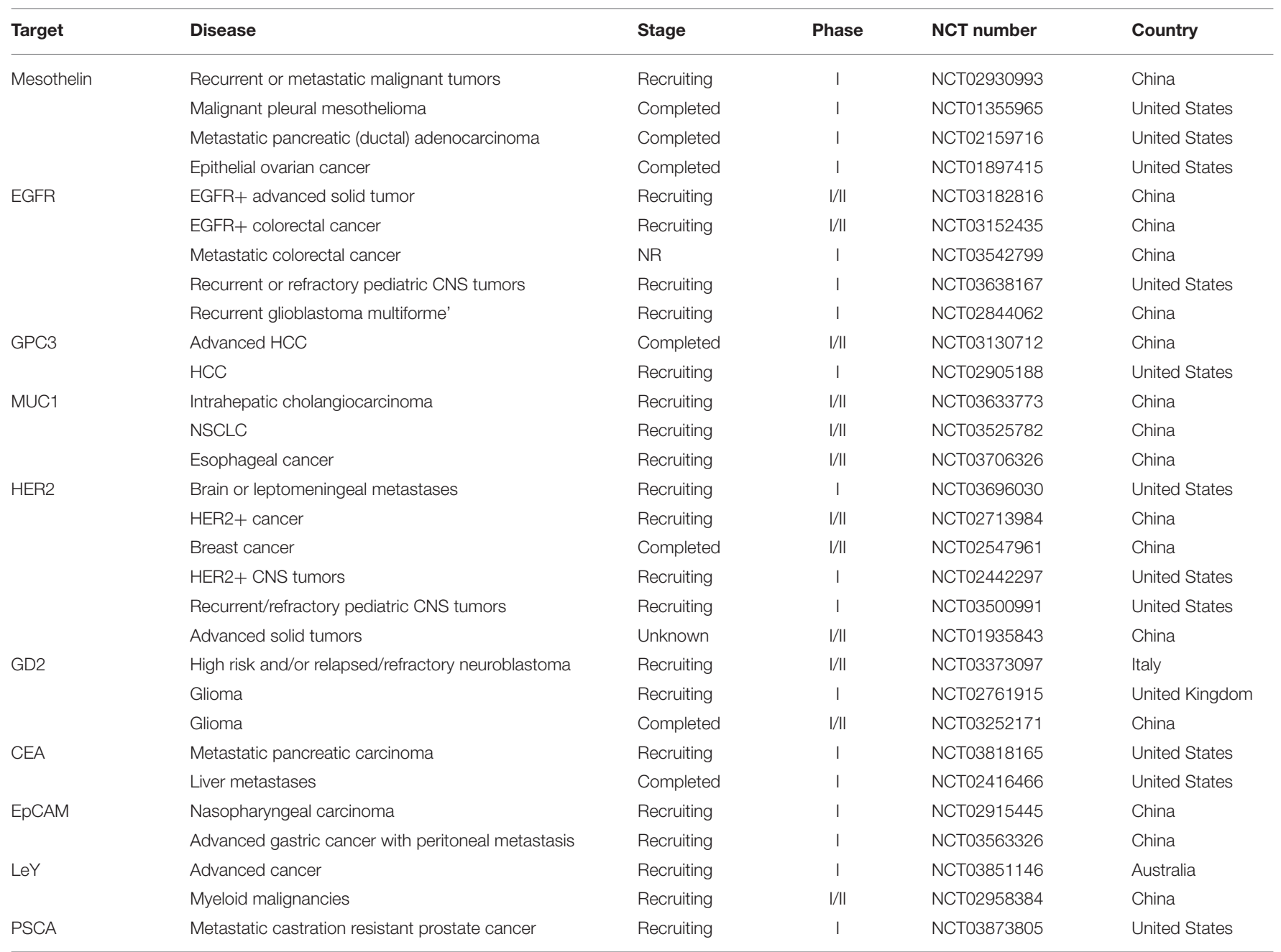

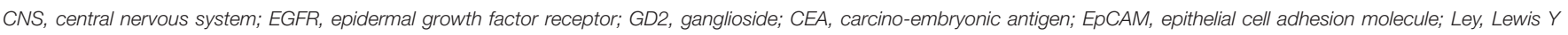
antigen; PSCA, prostate stem cell antigen; HCC, hepatocellular carcinoma; NR, not yet recruiting.

tissues but also in normal tissues. This poses another challenge in the treatment of solid tumors with CAR-T cells (61). In addition, the homing and activation of CAR-T cells in solid tumors are also challenging. How to make CAR-T cells accurately home from the peripheral blood to function at the tumor site needs to be solved urgently, but a single CAR-T cell therapy will not solve this problem. Moreover, CAR-T cells can coexpress some cytokines to enhance their killing activity and homing function, such as IL-2, IL-7, and chemokine (C-C motif) ligand 19 (CCL19) (Table 5).

Researchers from the Department of Neurosurgery, Perelman School of Medicine at the University of Pennsylvania used CAR-T cells to target the tumor-specific antigen EGFRvIII to treat patients (43). In this study, the authors found two major challenges with this technique: one problem is that the expression of EGFRvIII in the tumor tissues of patients is quite variable; the other is that the TME has a strong immunosuppressive effect, which will gradually become more concerning over the course of treatment. Therefore, the authors believe that it is necessary to search for new tumor antigens and drugs to overcome these immunosuppressive effects simultaneously to achieve the killing of tumor tissue. This also explains why CAR-T cell therapy is ineffective in treating gliomas: the immunosuppressive effects of the TME and the complexity of gene mutations (43).

$\mathrm{T}$ cells are picky about their environment and die within a few days without proper nutrients. In addition, tumor tissue releases self-defensive chemicals that block the normal functioning of $\mathrm{T}$ cells. Researchers at the Fred Hutchinson Cancer Research Center used a synthetic receptor "skeleton" to coat cancerspecific T cells and nutrients to kill tumor cells in mouse model (99). The results showed that the cytoskeleton coated T cells could effectively reduce tumor size in mice with pancreatic cancer and melanoma, and the therapeutic effect was stronger than that of injecting $\mathrm{T}$ cells alone. Of course, this approach is still a long way from clinical application (99).

\section{Future Improvements}

Scientists have developed a variety of ways to improve the anticancer efficacy of CAR-T cell therapy. CAR-T cells were 


\section{Current clinical target of CAR-T therapy in solid tumor}

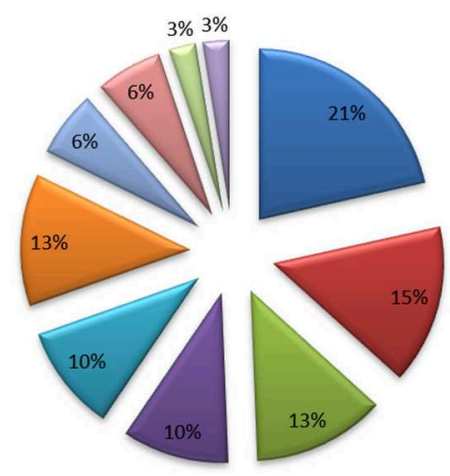

$\square$ mesothelin

aGFR

마군

aUC1

口 HER2

$\square \mathrm{GD} 2$

$\square$ CEA

$\square$ EPCAM

$\square$ LeY

$\square$ PSCA

FIGURE 4 | Current clinical targets for CAR-T therapy in solid tumors. The pie chart is based on the statistical result of CAR-T clinical trials for solid tumors registered on ClinicalTrials.gov.

further modified to secrete proinflammatory cytokines, thus protecting CAR-T cells in the inhibitory TME. Modified CAR$\mathrm{T}$ cells secreting IL-12 have achieved encouraging results in a mouse model (100). To improve the persistence of CAR-T cells, scientists constructed a dual-receptor CAR, which enables engineered $\mathrm{T}$ cells to express two artificial receptors, one for TAA recognition and the other for cytokine-mediated growth stimulation of $\mathrm{T}$ cells. CAR-T cells are subject to suppressive immune checkpoint signals in the TME, such as PD-L1 or CTLA4. These inhibitory receptor-ligand interactions can be blocked by monoclonal antibodies, thus eliminating the inhibition of $\mathrm{T}$ cells. CAR-T cells targeting tumor vessels are being studied for the treatment of melanoma and renal cancer. The presence of angiogenic growth factors (such as VEGF) in the TME and the overexpression of their receptors in tumor cells are associated with poor prognosis and metastasis (101). One potential reason for the failure of CAR-T cell therapy relates to the persistence of CAR-T cells; strategies such as the replacement of the costimulatory domain of $4-1 \mathrm{BB}$ and increased production of cytokines that stimulate $\mathrm{T}$ cell proliferation and activation have potential.

New CAR-T targets are necessary for the treatment of patients with hematological malignancies that do not express CD19. In addition, some patients treated with CD19-CAR-T cell therapy will relapse due to mutations that allow tumor escape. Currently, the most promising targets for the treatment of hematological malignancies include CD22, CD20, ROR1, immunoglobulin kappa chain, BCMA, and CD138 (for plasma malignancies) as well as CD33, CD123, and LeY (for myeloid malignancy).

There are many gene-editing tools, including zinc finger nucleases (ZFNs), meganucleases, transcription activator-like (TAL) effector nucleases (TALENs), and the Clustered regularly interspaced short palindromic repeats-associated protein 9

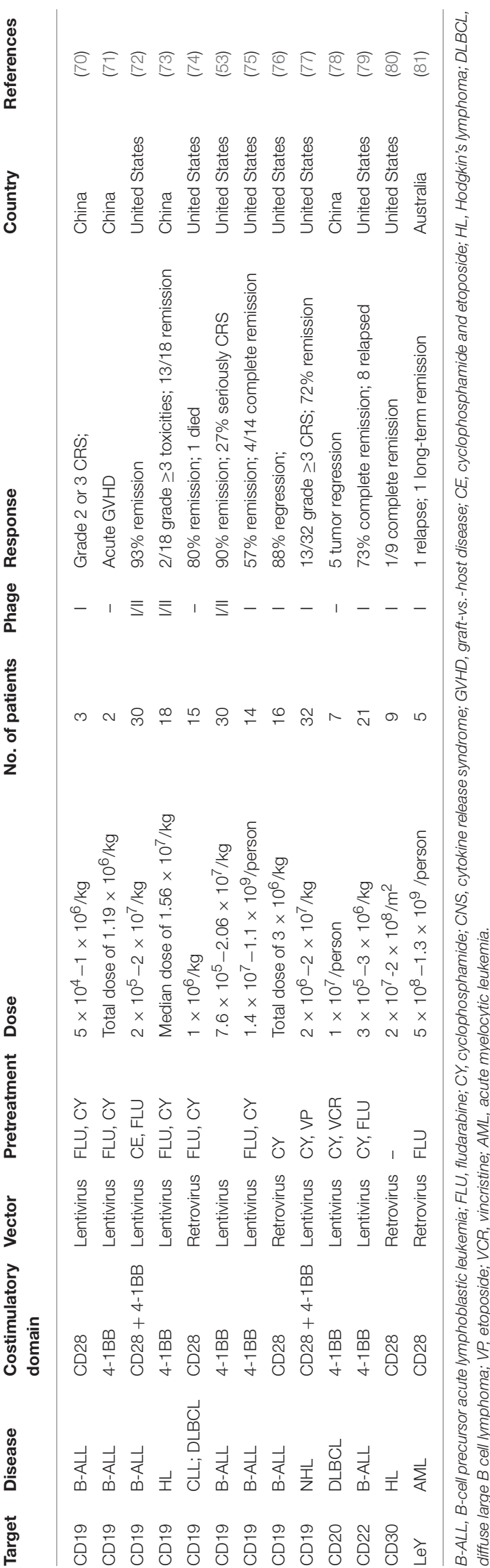


TABLE 5 | Published clinical targets of CAR-T therapy for solid tumors.

\begin{tabular}{|c|c|c|c|c|c|c|c|c|c|c|}
\hline Target & Disease & $\begin{array}{l}\text { Costimulatory } \\
\text { domain }\end{array}$ & Vector & Pretreatment & Dose & $\begin{array}{c}\text { No. of } \\
\text { patients }\end{array}$ & Phage & Response & Country & References \\
\hline EGFRvIII & Glioblastoma & $4-1 \mathrm{BB}$ & Lentivirus & $\begin{array}{l}\text { Temozolomide } \\
\text { radiation }\end{array}$ & $1-5 \times 10^{8} /$ person & 10 & । & 5 remission & United States & (43) \\
\hline EGFR & NSCLC & $4-1 \mathrm{BB}$ & Lentivirus & $\mathrm{CY}, \mathrm{CDDP}$ & $4.5 \times 10^{6}-1.09 \times 10^{7} / \mathrm{kg}$ & 11 & $1 / 11$ & 7/11 remission; & China & (83) \\
\hline GD2 & NB & NA & Retrovirus & - & $2 \times 10^{7}-1 \times 10^{8} / \mathrm{m}^{2}$ & 19 & । & 11/19 remission & United States & (84) \\
\hline GD2 & $\begin{array}{l}\text { Metastatic } \\
\text { melanoma }\end{array}$ & $\mathrm{CD} 28+\mathrm{OX} 40$ & Retrovirus & $\mathrm{FLU}, \mathrm{CY}$ & $1-2 \times 10^{7} / \mathrm{m}^{2}$ & 4 & । & 4 partial response & South Australia & (85) \\
\hline IL13R $\alpha 2$ & GBM & NA & $\begin{array}{l}\text { DNA } \\
\text { electroporation }\end{array}$ & - & $10.6 \times 10^{8} /$ person & 13 & । & 3 relapse & United States & (86) \\
\hline IL13R $\alpha 2$ & GBM & $4-1 \mathrm{BB}$ & Lentivirus & - & $\begin{array}{l}\text { Total dose of } 5.2-9.2 \times \\
10^{7} / \text { person }\end{array}$ & 1 & । & 1 relapse & United States & (87) \\
\hline HER2 & PNET; DSRCT & CD28 & Retrovirus & Chemotherapy & $1 \times 10^{4}-1 \times 10^{8} / \mathrm{m}^{2}$ & 19 & $|/| \mid$ & 1 necrosis; 4/19 remission; & United States & (88) \\
\hline CAIX & $\mathrm{RCC}$ & NA & Retrovirus & - & $3 \times 10^{8}-2.1 \times 10^{9} /$ person & 11 & - & - & Netherlands & (89) \\
\hline CAIX & $\mathrm{RCC}$ & NA & Retrovirus & - & $6 \times 10^{8}-4 \times 10^{9} /$ person & 12 & - & - & Netherlands & (90) \\
\hline Mesothelin & PAC; MPM & $4-1 \mathrm{BB}$ & $\begin{array}{l}\text { mRNA } \\
\text { electroporation }\end{array}$ & - & Total dose of $1.2 \times 10^{9} /$ person & 4 & - & 1 allergic reactions and cardiac arrest & United States & (91) \\
\hline Mesothelin & MPM; PDA & $4-1 \mathrm{BB}$ & $\begin{array}{l}\text { mRNA } \\
\text { electroporation }\end{array}$ & Chemotherapy & $\begin{array}{l}4.4 \times 10^{9} \text { of one patient; } 3.1 \times \\
10^{9} / \mathrm{m}^{2} \text { of another }\end{array}$ & 2 & । & 1 partial response & United States & (92) \\
\hline MUC1 & $\begin{array}{l}\text { Seminal vesicle } \\
\text { cancer }\end{array}$ & $\mathrm{CD} 28+4-1 \mathrm{BB}$ & Lentivirus & - & $\begin{array}{l}\text { Intratumoral injection of } 5 \times 10^{5} \\
\text { cells at two sites, respectively }\end{array}$ & 1 & । & no side effects & China & (93) \\
\hline CEA & $\mathrm{mCRC}$ & CD28 & Lentivirus & $\mathrm{CY}, \mathrm{FLU}$ & $2.5 \times 10^{7}-1.52 \times 10^{10} /$ person & 10 & । & $70 \%$ remission & China & (44) \\
\hline CEA & Liver metastases & CD28 & Retrovirus & - & $1 \times 10^{8}-3 \times 10^{10} /$ person & 6 & । & 5 patients died of progressive disease; & United States & (94) \\
\hline CEA & $\begin{array}{l}\text { Adenocarcinoma; } \\
\text { PMP }\end{array}$ & NA & - & FLU, CY & $1 \times 10^{9}-5 \times 10^{10} /$ person & 14 & । & Transient acute respiratory toxicity & United Kingdom & (40) \\
\hline BCMA & MM & $\mathrm{CD} 28$ & Retrovirus & CY, FLU & $3 \times 10^{5}-9 \times 10^{6} / \mathrm{kg}$ & 12 & । & $\begin{array}{l}1 \text { relapse after } 17 \text { weeks; } 1 \text { complete } \\
\text { remission }\end{array}$ & United States & (95) \\
\hline c-Met & Breast cancer & 4-1BB & $\begin{array}{l}\text { mRNA } \\
\text { electroporation }\end{array}$ & - & $3 \times 10^{7}-3 \times 10^{8} /$ person & 6 & - & Tumor necrosis at the injection site & United States & (96) \\
\hline PSMA & $\mathrm{PCa}$ & NA & Retrovirus & Chemotherapy & $1 \times 10^{9}-1 \times 10^{10} /$ person & 5 & । & 2/5 partial remission & United States & (97) \\
\hline TAG72 & $\mathrm{CRC}$ & NA & Retrovirus & - & $3-3.11 \times 10^{10} /$ person & 16 & । & Low-grade CRS & United States & (98) \\
\hline
\end{tabular}

CDDP, cis-diamminedichoro platinum; NB, neuroblastoma; GBM, glomerular basement membrane; PNET, primitive neuroectodermal tumors; DSRCT, desmoplastic small round cell tumor; PAC, perennial allergic colitis; MPM, malignant pleural mesothelioma; PDA, patent ductus arteriosus; $M C R C$, metastatic colorectal cancer; PMP, pseudomyxoma peritonei; MM, multiple myeloma; PCa, prostate cancer; CRC, colorectal cancer; CAIX, carbonic anhydrase IX, c-Met, c-mesenchymal-epithelial transition; PSMA, prostate-specific membrane antigen; TAG72, tumor-associated glycoproteins-72; NA, not applicable. The first generation of CAR contains a CD3 signaling domain. 
(CRISPR-Cas9 nuclease) (38). These techniques have been successfully applied in the study of engineered T cells. Due to the rapid development of this field, universal CAR-T cells may eventually be widely used. The manufacturing process for universal CAR-T cell therapy is simpler, and it is expected to achieve faster and more inexpensive off-the-shelf cell therapy products.

Challenges in this process include the selection of target antigens, the management of toxicity, and the regulation of the immunosuppressive TME. Many researchers are actively developing CAR-T cell therapies to achieve the same success in other hematological malignancies and solid tumors.

\section{TCR-T CELL THERAPY}

Both TCR and CAR-therapies modify the patient's own T lymphocytes ex vivo and then inject them back into the patient's body to kill cancer, but their mechanisms for recognizing antigens are quite different. TCRs use heterodimers consisting of alpha and beta peptide chains to recognize polypeptide fragments presented by MHC molecules (Figure 5) (102). CAR-T cells, on the other hand, use antibody fragments that bind to specific antigens on the surface of cancer cells. The target antigens identified by CAR-T cell therapy are all cell surface proteins, while TCR-T cell therapy can recognize intracellular antigen fragments presented by MHC molecules (102), so TCR-T cell therapy has a wider range of targets. However, TCR-T cell therapy is $\mathrm{MHC}$ restricted and depends on presentation by $\mathrm{MHC}$ molecules to recognize targets and activate $\mathrm{T}$ cell function, so these traits are also a disadvantage of TCR-T cell therapy.

Dr. Michael Steinmetz first transferred TCR genes from one $\mathrm{T}$ cell to another, giving the second $\mathrm{T}$ cell the same antigen specificity (103). This process is the origin of current TCR gene therapy. The TCR is a specific receptor and a characteristic marker on the surface of T cells. TCR-T cells are genetically engineered TCR products that can recognize specific antigens. The core goal behind TCR-T cell technology is to directly modify TCR binding to tumor antigens. The affinity of human TCRs to these antigens is relatively low, which makes it impossible to recognize and kill tumors effectively. The artificially designed high-affinity TCR is encoded in T cells by genetic engineering technology (54), which enhances both specificity recognition and affinity during the recognition of tumor cells by $\mathrm{T}$ cells.

The construction of high-affinity TCR-T cells requires the identification of specific targets. First, the polypeptides presented by cancer cells are identified, and then the polypeptides presented in normal tissues are screened out. After the target is confirmed, a TCR phage display library is established to screen TCRs with high affinity and specificity. A preclinical safety test is then performed to ensure minimal off-target effects and cross-reactivity.

In one report, after modifying several key amino acids, the resulting TCR had a greatly increased affinity for a common cancer antigen [tumor-associated antigen (TAA)], New York esophageal squamous cell carcinoma (NY-ESO-1), and this TCR can be used to attack NY-ESO-1-overexpressing cancers, such as multiple myeloma (104). In this clinical trial, $80 \%$ of patients with multiple myeloma had a good clinical response, and $70 \%$ of them had a complete or near-complete response (104).

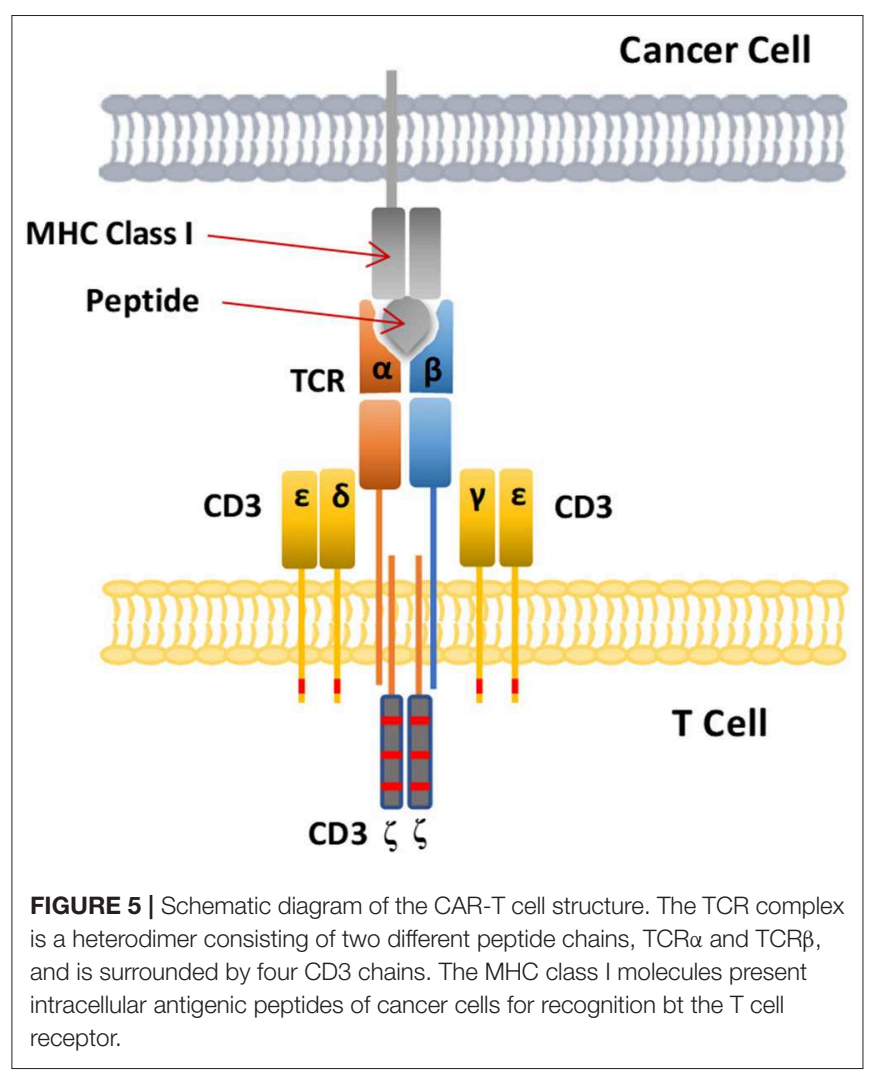

\section{Advantages and Challenges of TCR-T Cell Therapy}

Any antigen that can be presented by MHC molecules can be recognized by TCR-T cells, whether it is an intracellular or cell surface antigen or a neo-antigen produced by tumor cells after mutation. TCRs can recognize the internal molecules of cancer cells, and TCR-T cells can have greatly improved affinity for cancer cells through genetic engineering. Because they retain all the auxiliary molecules of the TCR signal transduction pathway, TCR-T cells can be fully activated when a small amount of antigen is present, resulting in a killing effect $(26,82)$.

Difficulties in the development of TCR-T cell technology include the selection of good targets, the search for specific TCRs, screening for optimal TCR affinity, safety evaluation, time, and cost. Target selection is one of the most important aspects (82). These problems have become barriers to TCR-T cell therapy, and finding a solution to these problems has become the key to determining the success of TCR-T cells.

Most TCR-T cell therapy targets are limited by MHC class. In addition, there is a risk of hybridization (mismatch) between exogenous and endogenous chains, which may induce harmful recognition of autoantigens, leading to graft-vs.-host disease. Increased TCR affinity poses a risk of false targeting, so TCR-T cell therapy should be applied carefully. TCR-T cell therapy has shown some therapeutic potential, but there are still many limitations, such as the matching of histocompatibility antigens and the need for antigens to be presented on the cell surface. 
TABLE 6 | Current clinical targets of TCR-T therapy for hematological malignancies (ClinicalTrials.gov).

\begin{tabular}{|c|c|c|c|c|c|}
\hline Target & Disease & Stage & Phase & NCT number & Country \\
\hline $\mathrm{HA}-1$ & Relapsed or refractory acute leukemia after donor stem cell & Recruiting & 1 & NCT03326921 & United States \\
\hline WT1 & Myelodysplastic syndromes and acute myeloid leukemia patients & Completed & $\mathrm{l} / \mathrm{II}$ & NCT02550535 & Germany \\
\hline WT1 & Acute myeloid leukemia & Active & $|/| \mid$ & NCT02770820 & United States \\
\hline CMV & Hematological malignancies and CMV infection & Suspended & I & NCT02988258 & United Kingdom \\
\hline
\end{tabular}

CMV, cytomegalovirus; HA-1, a protein that present on the surface of blood cells; WT1, Wilms tumor 1.

TABLE 7 | Current clinical targets of TCR-T therapy for solid tumors (ClinicalTrials.gov).

\begin{tabular}{|c|c|c|c|c|c|}
\hline Target & Disease & Stage & Phase & NCT number & Country \\
\hline \multirow[t]{2}{*}{ MAGE } & Solid and hematological malignancies; & Enrolling & - & NCT03391791 & Canada \\
\hline & Metastatic renal cancer and melanoma; & Terminated & $1 / I I$ & NCT01273181 & United States \\
\hline \multirow[t]{2}{*}{ Gp100 } & Metastatic melanoma; & Completed & $\|$ & NCT00923195 & United States \\
\hline & Malignant melanoma; & Terminated & $\|$ & NCT02889861 & United Kingdom \\
\hline MART-1 & Skin metastatic melanoma & Completed & I & NCT00091104 & United States \\
\hline \multirow[t]{2}{*}{ HPV-16 E6 } & HPV+ NHSCC or cervical cancer; & Recruiting & 1 & NCT03578406 & China \\
\hline & HPV-associated cancer; & Completed & $1 / I I$ & NCT02280811 & United States \\
\hline \multirow[t]{3}{*}{ NY-ESO-1 } & Ovarian, fallopian tube, or primary peritoneal cancer; & Recruiting & I & NCT03691376 & United States \\
\hline & Advanced NSCLC; & Recruiting & 1 & NCT03029273 & China \\
\hline & Sarcoma; & Recruiting & I & NCT03462316 & China \\
\hline HBV & Hepatocellular & Recruiting & I & NCT02719782 & China \\
\hline P53 & Metastatic cancer that overexpresses p53 & Completed & $\|$ & NCT00393029 & United States \\
\hline CEA & Metastatic cancer; & Terminated & 1 & NCT00923806 & United States \\
\hline HPV E7 & Human papillomavirus-associated cancers & Recruiting & $1 / I I$ & NCT02858310 & United States \\
\hline SL9 & HIV & Completed & 1 & NCT00991224 & United States \\
\hline TGF $\beta \|$ & Metastatic colorectal cancer & Terminated & $\mid / I I$ & NCT03431311 & Norway \\
\hline MCPyV & Metastatic or unresectable Merkel cell cancer & Recruiting & $|/| \mid$ & NCT03747484 & United States \\
\hline TRAIL & Metastatic renal cancer & Terminated & I & NCT00923390 & United States \\
\hline PRAME & AML/MDS or metastatic uveal melanoma & Active & $1 / 11$ & NCT02743611 & United States \\
\hline EBV & Recurrent or metastatic NPC & NR & $\|$ & NCT03648697 & China \\
\hline CMV & Hematological malignancies and CMV infection & Suspended & 1 & NCT02988258 & United Kingdom \\
\hline \multirow[t]{2}{*}{ KRAS } & KRAS G12V + tumor; & Recruiting & $\mid / I I$ & NCT03190941 & United States \\
\hline & KRAS G12D + tumor; & Recruiting & $|/| \mid$ & NCT03745326 & United States \\
\hline
\end{tabular}

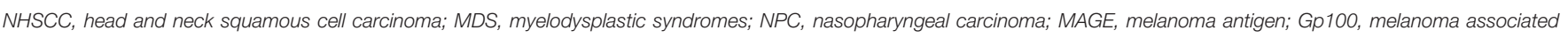
antigen; MART1, melanoma antigen recognized by T cells 1; HPV-16-E6, human papillomavirus-16 E6 protein; NR, not yet recruiting.

\section{Current Clinical Targets of TCR-T Cell Therapy in Hematological Malignancies}

Specific targeted immunotherapy of leukemic stem cells is an ideal method for the treatment of malignant myeloid tumors (Table 6), but the appropriate epitopes are still unclear. The comparative proteomic characteristics of hematopoietic stem cells and progenitor cells from healthy stem cell donors and patients with acute myeloid leukemia may reveal differentially expressed proteins that can be used as surface markers or as substitutes for affected molecular pathways.

\section{Current Clinical Targets of TCR-T Cell Therapy in Solid Tumors}

$T$ cells activated by TCRs can target most tumor-specific antigens, especially those antigens that are intracellular. Therefore, many TCR-T cell techniques have been applied in clinical trials of solid tumors (Table 7 and Figure 6). Because of their relatively isolated physiological locations and unique immunosuppressive microenvironments, immunotherapy is less effective for solid tumors than for hematological tumors. To overcome the isolated physiological locations of solid tumors, local injection of $\mathrm{T}$ cells into tumors was used in a mouse model (105). The effect from local injection is better than that achieved by systemic drug administration, such as injecting $\mathrm{T}$ cells into the cerebrospinal fluid in brain tumors.

\section{Published Clinical TCR-T Cell Therapies in Hematological Malignancies}

The clinical application of gene-modified $\mathrm{T}$ cell therapy has led to unprecedented response rates in leukemia and lymphoma patients treated with anti-CD19 CAR-T cells. Although CAR$\mathrm{T}$ cell therapy has shown significant efficacy in $\mathrm{CD} 19+$ 


\section{Current clinical target of TCR-T therapy in solid tumor}
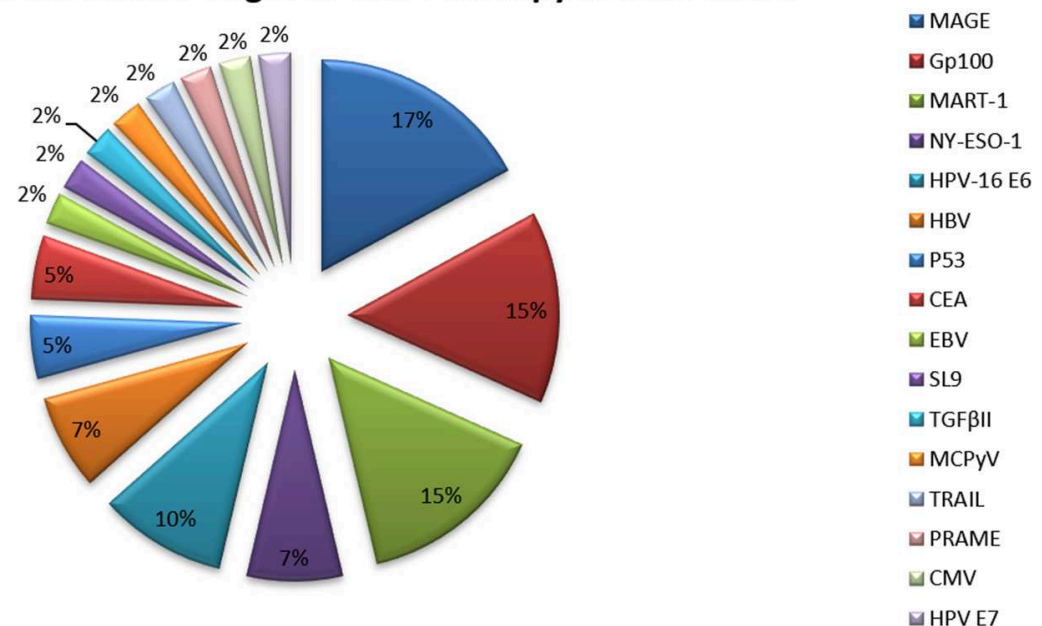

FIGURE 6 | Current clinical targets for TCR-T therapy in solid tumors (ClinicalTrials.gov). The pie chart is based on the statistical result of TCR-T clinical trials for solid tumors registered on ClinicalTrials.gov.

TABLE 8 | Published clinical TCR-T therapy for hematological malignancies.

\begin{tabular}{|c|c|c|c|c|c|c|c|c|c|}
\hline Target & Disease & Vector & Pretreatment & Dose & $\begin{array}{c}\text { No. of } \\
\text { patients }\end{array}$ & Phage & Response & Country & Reference \\
\hline WT1 & $\begin{array}{l}\text { Acute myeloid } \\
\text { leukemia; MDS }\end{array}$ & Retrovirus & $\begin{array}{l}\text { Cytosine arabinoside } \\
\text { and aclarubicin }\end{array}$ & $\begin{array}{l}2 \times 10^{8}-5 \times \\
10^{9} / \text { person }\end{array}$ & 8 & I & $50 \%$ remission & Japan & $(106)$ \\
\hline
\end{tabular}

hematological cancers such as lymphoma and leukemia, lifethreatening side effects such as CRS and neurotoxicity limit the clinical application of CAR-T cell therapy. Eureka Therapeutics has published preclinical data on its proprietary antibody-TCR (AbTCR) platform, proving that AbTCR-T cells have the same anticancer effects as existing anti-CD19 CAR-T cells in a mouse model (102); however, the production of inflammatory cytokines is significantly reduced in AbTCR-T cells, reducing the risk of CRS. Safer T cell therapy can provide patients with a larger therapeutic window while reducing the direct and indirect costs for patients and the entire health care system (Table 8).

\section{Published Clinical TCR-T Cell Therapies in Solid Tumors}

Researchers isolated endogenous TCRs, engineered them, and introduced these modified $\mathrm{T}$ cells into the human body. In this way, the number of $\mathrm{T}$ cells with the ability to target cancer cells will increase, and this is expected to help identify and target multiple solid tumors and hematological tumors (Table 9).

\section{Differences Between CAR-T Cell and TCR-T Cell Therapies}

CARs can recognize not only peptide antigens but also carbohydrate and glycolipid antigens, which enlarges the pool of targetable cancer antigens. CAR-T cell therapy is not restricted by MHC class. CAR-T cells can target nonprotein glycolipid antigens of cancer cells to recognize antigens in multiple dimensions. The problem with the treatment of solid and hematological tumors by CAR-T cells is that the target antigens are all cell surface proteins. Even if CAR-T cells have a potent killing effect on tumor cells, without appropriate, specific cell surface target proteins, CAR-T cell therapy cannot have a real impact. Because MHC molecules can present peptide chains obtained from the cell surface or intracellular proteins, TCRs can target more antigens than CARs. These antigens, including CEA, HER-2, CD19, gp100, MART-1, MAGA-A3, and NY-ESO1 , are suitable for TCR-T cell therapy. TCRs target intracellular proteins with tumor specificity. These antigens include neoantigens generated by random mutations in tumor DNA and so-called cancer testis antigens (82). These antigens are usually expressed in only some tumors and genital tissues, while MHC molecules are not expressed in genital tissues. TILs and TCRs can recognize only the antigens presented by specific MHC molecules and may escape immune surveillance due to the downregulation or mutation of MHC molecules in tumor cells, resulting in clinical limitations (25). TCR-based therapies may be superior to CAR-based therapies because TCR-T cells use natural T cell signaling mechanisms (112).

The dosage of CAR-T cell therapy is two to three orders of magnitude lower than that needed with TILs and TCR-T cells. Because CAR-T cell therapies have a clear target and a high specificity for recognizing tumor surface antigen and are able to overcome $\mathrm{MHC}$ restriction, the number of single transfusion cells needed for CAR-T cell therapy is far smaller than that needed for TCR-T cell therapy or TIL therapy to generate the same therapeutic effect. 
TABLE 9 | Published clinical TCR-T therapy for solid tumors.

\begin{tabular}{|c|c|c|c|c|c|c|c|c|c|}
\hline Target & Disease & Vector & Pretreatment & Dose & $\begin{array}{c}\text { No. of } \\
\text { patients }\end{array}$ & Phage & Response & Country & References \\
\hline MART-1 & $\begin{array}{l}\text { Metastatic } \\
\text { melanoma }\end{array}$ & Retrovirus & Chemotherapy & $\begin{array}{l}1.5 \times 10^{9}-1.07 \times \\
10^{11} \text { /person }\end{array}$ & 20 & $\|$ & $\begin{array}{l}30 \% \text { objective } \\
\text { antitumor response }\end{array}$ & United States & $(107)$ \\
\hline Gp100 & $\begin{array}{l}\text { Metastatic } \\
\text { melanoma }\end{array}$ & Retrovirus & Chemotherapy & $\begin{array}{l}1.8 \times 10^{9}-1.1 \times \\
10^{11} / \text { person }\end{array}$ & 16 & $\|$ & $\begin{array}{l}\text { 19\% objective } \\
\text { antitumor response }\end{array}$ & United States & $(107)$ \\
\hline CEA & $\begin{array}{l}\text { Metastatic } \\
\text { colorectal }\end{array}$ & Retrovirus & Chemotherapy & $2-4 \times 10^{8} /$ person & 3 & - & Grade 2/3 diarrhea & United States & $(108)$ \\
\hline NY-ESO-1 & $\begin{array}{l}\text { Metastatic } \\
\text { melanoma/synovial } \\
\text { cell sarcoma }\end{array}$ & Retrovirus & Chemotherapy & $\begin{array}{l}1.6 \times 10^{10}-1.3 \times \\
10^{11} / \text { person }\end{array}$ & 17 & l & $\begin{array}{l}2 \text { complete } \\
\text { remission; } 1 \text { partial } \\
\text { remission }\end{array}$ & United States & (109) \\
\hline NY-ESO-1 & Multiple myeloma & Lentivirus & Chemotherapy & $\begin{array}{l}\text { Average dose of } 2.4 \\
\times 10^{9} / \text { person }\end{array}$ & 20 & $|/| \mid$ & $80 \%$ remission; & United States & $(104)$ \\
\hline MAGE-A3 & $\begin{array}{l}\text { Metastatic } \\
\text { melanoma/multiple } \\
\text { myeloma }\end{array}$ & Lentivirus & CY & $\begin{array}{l}2.4-5.3 \times \\
10^{9} / \text { person }\end{array}$ & 2 & III/IV & $\begin{array}{l}2 \text { died for cardiac } \\
\text { toxicity }\end{array}$ & United States & $(110)$ \\
\hline MAGE-A4 & $\begin{array}{l}\text { Esophageal } \\
\text { cancer }\end{array}$ & Retrovirus & $\begin{array}{l}\text { Surgery; radiotherapy; } \\
\text { chemotherapy }\end{array}$ & $\begin{array}{l}2 \times 10^{8}-5 \times \\
10^{9} / \text { person }\end{array}$ & 10 & 1 & $\begin{array}{l}\text { 7/10 tumor } \\
\text { progression }\end{array}$ & Japan & $(111)$ \\
\hline
\end{tabular}

\section{DISCUSSION}

Immunotherapy, unlike traditional therapies, directly acts on cancer cells by recruiting the autoimmune system and using it to attack tumors. The anti-tumor immune response can continuously recognize and memorize tumor antigens and increasingly expand with time; this cycle can be repeated to strengthen the anti-tumor immune response. With expansion of the immune response, some cytotoxic $\mathrm{T}$ cells differentiate into mature memory $\mathrm{T}$ cells, which can provide long-term immune memory even when primary antigen stimulation does not exist. Therefore, immunotherapy can bring lasting benefits and longterm survival to patients.

The development of a new drug or therapy is not easy, and it often costs billions of dollars. Juno Therapeutics is committed to the research of tumor cell immunity and is one of the pioneers in this field. At present, research on CAR-T cell products targeting CD19 is relatively extensive, and the two approved products target CD19 for the treatment of hematological tumors. Globally, the R\&D pipeline of CAR-T cells has expanded rapidly, including the exploration of new targets, such as BCMA, CD123, and CD33, as well as the expansion to new indications, such as the progression of hematological tumors to solid tumors. A number of companies around the world have been pushing their projects to the clinical stage, and it is expected that there will be CAR$\mathrm{T}$ cell products for different tumors in the future. With the promotion of new structures in clinical trials and improvements in production technology, the third and fourth generations of CAR-T cell products are expected to have better efficacy. TCR$\mathrm{T}$ therapies targeting solid tumor targets such as WT-1, L1CAM, ROR-1, MUC-16, LewisY, HPV-16, etc. are also undergoing clinical trials. For solid tumors, TCR-T therapies may be more advantageous. Many companies around the world such as Kite Pharma, JunoTherapeutics, Adaptimmune Therapeutics, etc. are all committed to the development of TCR-T immunotherapy, hoping to bring feasible treatment plans.
The preparation of engineered $\mathrm{T}$ cells still depends on traditional manual operation, such that cell quality and stability are difficult to guarantee. Moreover, the curative effect is greatly reduced. With the continuous improvement of engineered $\mathrm{T}$ cell technologies, it is foreseeable that automatic production of engineered $\mathrm{T}$ cells will be a major trend in the future. We also look forward to engineered $\mathrm{T}$ cell therapy becoming more technically mature, safer, and efficient. Tumor immunotherapy will bring hope to many cancer patients soon. Some of the greatest challenges in developing cell therapies include the lack of preclinical models to assess the safety and efficacy of these complex therapies and the responses to safety issues identified in early clinical studies. In addition, there are still many obstacles in the treatment of solid tumors.

It is expected that, due to technological advances in engineering $\mathrm{T}$ cells, gene editing, and cell manufacturing, the foundations of $\mathrm{T}$ cell-based therapies will be extended to other cell types in the future, such as induced pluripotent stem cells, hematopoietic stem cells, and NK cells. The indications will also transcend cancer and are expected to include infectious diseases, organ transplantation, and autoimmune diseases.

\section{AUTHOR CONTRIBUTIONS}

LZ drafted the manuscript, during which she received carefully guidance and support from YC. All authors read and approved the final manuscript.

\section{FUNDING}

This work was supported by the National Natural Science Foundation of China (Grants 31741042 and 81872783), the Guangdong Natural Science Foundation (Grant 2018A030313916), and the Shenzhen Science and Technology Innovation Program (Grants JCYJ20170818090043031 and JCYJ20180504165501371). 


\section{REFERENCES}

1. Scarfò I, Maus MV. Current approaches to increase CAR T cell potency in solid tumors: targeting the tumor microenvironment. J Immunother Cancer. (2017) 5:28. doi: 10.1186/s40425-017-0230-9

2. Hendifar AE, Hingorani SR, Harris WP, Seery TE, Sigal D, Wu W, et al. LBA-02 high response rate and PFS with PEGPH20 added to Nab-Paclitaxel/Gemcitabine in stage IV previously untreated pancreatic cancer patients with high-HA tumors: interim results of a randomized phase 2 study. Ann Oncol. (2015) 26(Suppl. 4):iv117. doi: 10.1093/annonc/ $\operatorname{mdv} 262.02$

3. Ren J, Liu X, Fang C, Jiang S, June CH, Zhao Y. Multiplex genome editing to generate universal CAR T cells resistant to PD1 inhibition. Clin Cancer Res. (2017) 23:2255-66. doi: 10.1158/1078-0432.CCR-16-1300

4. Crespo J, Sun H, Welling TH, Tian Z, Zou W. T cell anergy, exhaustion, senescence, and stemness in the tumor microenvironment. Curr Opin Immunol. (2013) 25:214-21. doi: 10.1016/j.coi.2012.12.003

5. Andrikou K, Peterle C, Pipitone S, Salati M, Cascinu S. Emerging antibodies for the treatment of pancreatic cancer. Exp Opin Emerg Drugs. (2017) 22:39-51. doi: 10.1080/14728214.2017.1293649

6. Perica K, Varela JC, Oelke M, Schneck J. Adoptive T cell immunotherapy for cancer. Rambam Maimonides Med J. (2015) 6:e0004. doi: 10.5041/RMMJ.10179

7. Renfro LA, An MW, Mandrekar SJ. Precision oncology: a new era of cancer clinical trials. Cancer Lett. (2016) 387:1216. doi: 10.1016/j.canlet.2016.03.015

8. Bernadic M Jr, Duchon R, Aziri R, Mladosievicova B. New principles of cancer therapy give new hope for oncological patients. Bratisl Lek Listy. (2019) 120:15-8. doi: 10.4149/BLL_2019_002

9. Reck M, Mok TSK, Nishio M, Jotte RM, Cappuzzo F, Orlandi F, et al. Atezolizumab plus bevacizumab and chemotherapy in nonsmall-cell lung cancer (IMpower150): key subgroup analyses of patients with EGFR mutations or baseline liver metastases in a randomised, open-label phase 3 trial. Lancet Respir Med. (2019) 7:387-401 doi: 10.1016/S2213-2600(19)30084-0

10. Frederickson AM, Arndorfer S, Zhang I, Lorenzi M, Insinga R, Arunachalam A, et al. Pembrolizumab plus chemotherapy in metastatic non-small-cell lung cancer. $N$ Engl J Med. (2018) 378:2078-92. doi: 10.1056/NEJMoa1801005

11. Socinski MA, Jotte RM, Cappuzzo F, Orlandi F, Stroyakovskiy D, Nogami $\mathrm{N}$, et al. Atezolizumab for first-line treatment of metastatic nonsquamous NSCLC. N Engl J Med. (2018) 378:2288-301. doi: 10.1056/NEJMoa 1716948

12. Cella D, Grünwald V, Escudier B, Hammers HJ, George S, Nathan P, et al. Patient-reported outcomes of patients with advanced renal cell carcinoma treated with nivolumab plus ipilimumab versus sunitinib (CheckMate 214): a randomised, phase 3 trial. Lancet Oncol. (2019) 20:297310. doi: 10.1016/S1470-2045(18)30778-2

13. Motzer RJ, Tannir NM, McDermott DF, Arén Frontera O, Melichar B, Choueiri TK, et al. Nivolumab plus Ipilimumab versus sunitinib in advanced renal-cell carcinoma. N Engl J Med. (2018) 378:127790. doi: 10.1056/NEJMoal712126

14. Tawbi HA, Forsyth PA, Algazi A, Hamid O, Hodi FS, Moschos SJ, et al. Combined nivolumab and ipilimumab in melanoma metastatic to the brain. New Engl J Med. (2018) 379:722-30. doi: 10.1056/NEJMoa1805453

15. Heyman B, Yang Y. New developments in immunotherapy for lymphoma. Cancer Biol Med. (2018) 15:189209. doi: 10.20892/j.issn.2095-3941.2018.0037

16. Vairy S, Garcia JL, Teira P, Bittencourt H. CTL019 (tisagenlecleucel): CAR-T therapy for relapsed and refractory B-cell acute lymphoblastic leukemia. Drug Des Devel Ther. (2018) 12:3885-98. doi: 10.2147/DDDT. S138765

17. Ramalingam SS, Yang JC, Lee CK, Kurata T, Kim DW, John T, et al. Osimertinib as first-line treatment of EGFR mutation-positive advanced non-small-cell lung cancer. J Clin Oncol. (2018) 36:8419. doi: 10.1200/JCO.2017.74.7576

18. Soria JC, Ohe Y, Vansteenkiste J, Reungwetwattana T, Chewaskulyong B, Lee $\mathrm{KH}$, et al. Osimertinib in untreated EGFR-mutated advanced non-small-cell lung cancer. N Engl J Med. (2018) 378:113-25. doi: 10.1056/NEJMoa 1713137

19. Mohan N, Shen Y, Endo Y, ElZarrad MK, Wu WJ. Trastuzumab, but not pertuzumab, dysregulates HER2 signaling to mediate inhibition of autophagy and increase in reactive oxygen species production in human cardiomyocytes. Mol Cancer Ther. (2016) 15:1321-31. doi: 10.1158/1535-7163.MCT-15-0741

20. Sammons SL, Topping DL, Blackwell KL. HR+, HER2- advanced breast cancer and CDK4/6 inhibitors: Mode of action, clinical activity, and safety profiles. Curr Cancer Drug Targets. (2017) 17:637-49. doi: 10.2174/1568009617666170330120452

21. McCain J. First-in-class CDK4/6 inhibitor palbociclib could usher in a new wave of combination therapies for HR+, HER2- breast cancer. P\&T. (2015) 40:511-20.

22. Sledge GW, Toi M, Neven P, Sohn J, Inoue K, Pivot X, et al. MONARCH 2: abemaciclib in combination with fulvestrant in women with HR+/HER2advanced breast cancer who had progressed while receiving endocrine therapy. J Clin Oncol. (2017) 35:2875-84. doi: 10.1200/JCO.2017.73.7585

23. Maus MV, Fraietta JA, Levine BL, Kalos M, Zhao Y, June CH. Adoptive immunotherapy for cancer or viruses. Ann Rev Immunol. (2014) 32:189225. doi: 10.1146/annurev-immunol-032713-120136

24. Gattinoni L, Powell DJ, Rosenberg SA, Restifo NP. Adoptive immunotherapy for cancer: building on success. Nat Rev Immunol. (2006) 6:38393. doi: $10.1038 /$ nri1842

25. Sadelain M, Riviere I, and Riddell S. Therapeutic T cell engineering. Nature. (2017) 545:423-31. doi: 10.1038/nature22395

26. Kershaw MH, Westwood JA, and Darcy PK. Gene-engineered T cells for cancer therapy. Nat Rev Cancer. (2013) 13:525-41. doi: 10.1038/nrc3565

27. Maude SL, Laetsch TW, Buechner J, Rives S, Boyer M, Bittencourt H, et al. Tisagenlecleucel in children and young adults with B-cell lymphoblastic leukemia. New Engl J Med. (2018) 378:439-45. doi: 10.1056/NEJMoa1709866

28. Neelapu SS, Locke FL, Bartlett NL, Lekakis LJ, Miklos DB, Jacobson CA, et al. Axicabtagene ciloleucel CAR T-cell therapy in refractory large B-cell lymphoma. N Engl J Med. (2017) 377:2531-44. doi: 10.1056/NEJMoa1707447

29. Mullard A. FDA approves first CAR T therapy. Nat Rev Drug Discov. (2017) 16:669. doi: 10.1038/nrd.2017.196

30. Kalos M, Levine BL, Porter DL, Katz S, Grupp SA, Bagg A, et al. T cells with chimeric antigen receptors have potent antitumor effects and can establish memory in patients with advanced leukemia. Sci Transl Med. (2011) 3:95ra73. doi: 10.1126/scitranslmed.3002842

31. Wang Z, Guo Y, Han W. Current status and perspectives of chimeric antigen receptor modified T cells for cancer treatment. Protein Cell. (2017) 8:896-925. doi: 10.1007/s13238-017-0400-z

32. Maus MV, June CH. Making better chimeric antigen receptors for adoptive T-cell therapy. Clin Cancer Res. (2016) 22:187584. doi: 10.1158/1078-0432.CCR-15-1433

33. Kenderian SS, Porter DL, Gill S. Chimeric antigen receptor $\mathrm{T}$ cells and hematopoietic cell transplantation: how not to put the CART before the horse. Biol Blood Marrow Transplant. (2017) 23:235-46. doi: 10.1016/j.bbmt.2016.09.002

34. Tang XY, Sun Y, Zhang A, Hu GL, Cao W, Wang DH, et al. Third-generation CD28/4-1BB chimeric antigen receptor $\mathrm{T}$ cells for chemotherapy relapsed or refractory acute lymphoblastic leukaemia: A non-randomised, open-label phase I trial protocol. BMJ Open. (2016) 6:e013904. doi: 10.1136/bmjopen-2016-013904

35. Zhang C, Liu J, Zhong, JF, Zhang X. Engineering CAR-T cells. Biomark Res. (2017) 5:22. doi: 10.1186/s40364-017-0102-y

36. Sadelain M, Brentjens R, Rivière I. The basic principles of chimeric antigen receptor design. Cancer Discov. (2013) 3:388-98. doi: 10.1158/2159-8290.CD-12-0548

37. Lee DW, Kochenderfer JN, Stetler-Stevenson M, Cui YK, Delbrook C, Feldman SA, et al. T cells expressing CD19 chimeric antigen receptors for acute lymphoblastic leukaemia in children and young adults: A phase 1 dose-escalation trial. Lancet. (2015) 385:517-28. doi: 10.1016/S0140-6736(14)61403-3

38. Zhao J, Lin Q, Song Y, Liu D. Universal CARs, universal $\mathrm{T}$ cells, and universal CAR T cells. J Hematol Oncol. (2018) 11:132. doi: 10.1186/s13045-018-0677-2 
39. Gardner RA, Finney O, Annesley C, Brakke H, Summers C, Leger K, et al. Intent-to-treat leukemia remission by CD19 CAR T cells of defined formulation and dose in children and young adults. Blood. (2017) 129:332231. doi: 10.1182/blood-2017-02-769208

40. Thistlethwaite FC, Gilham DE, Guest RD, Rothwell DG, Pillai M, Burt DJ, et al. The clinical efficacy of first-generation carcinoembryonic antigen (CEACAM5)-specific CAR T cells is limited by poor persistence and transient pre-conditioning-dependent respiratory toxicity. Cancer Immunol Immunother. (2017) 66:1425-36. doi: 10.1007/s00262-0172034-7

41. Kandalaft LE, Powell DJ, Coukos G. A phase I clinical trial of adoptive transfer of folate receptor-alpha redirected autologous $\mathrm{T}$ cells for recurrent ovarian cancer. J Transl Med. (2012) 10:157. doi: 10.1186/1479-587610-157

42. Deniger DC, Kwong ML, Pasetto A, Dudley ME, Wunderlich JR, Langhan $\mathrm{MM}$, et al. A pilot trial of the combination of vemurafenib with adoptive cell therapy in patients with metastatic melanoma. Clin Cancer Res. (2017) 23:351-362. doi: 10.1158/1078-0432.CCR-16-0906

43. O’Rourke DM, Nasrallah MP, Desai A, Melenhorst JJ, Mansfield K, Morrissette JJD, et al. A single dose of peripherally infused EGFRvIIIdirected CAR $\mathrm{T}$ cells mediates antigen loss and induces adaptive resistance in patients with recurrent glioblastoma. Sci Transl Med. (2017) 9:eaaa0984. doi: 10.1126/scitranslmed.aaa0984

44. Zhang C, Wang Z, Yang Z, Wang M, Li S, Li Y, et al. Phase I escalating-dose trial of CAR-T therapy targeting CEA(+) metastatic colorectal cancers. $\mathrm{Mol}$ Ther. (2017) 25:1248-58. doi: 10.1016/j.ymthe.2017.03.010

45. Fraietta JA, Nobles CL, Sammons MA, Lundh S, Carty SA, Reich TJ, et al. Disruption of TET2 promotes the therapeutic efficacy of CD19targeted T cells. Nature. (2018) 558:307-12. doi: 10.1038/s41586-0180178-z

46. Ruella M, Kenderian SS. Next-generation chimeric antigen receptor T-cell therapy: going off the shelf. Bio Drugs. (2017) 31:473-81. doi: 10.1007/s40259-017-0247-0

47. Cohen AD. CAR $\mathrm{T}$ cells and other cellular therapies for multiple myeloma: 2018 update. Am Soc Clin Oncol Educ Book. 2018:e615. doi: 10.1200/EDBK_200889

48. Johnson LA, June CH. Driving gene-engineered $\mathrm{T}$ cell immunotherapy of cancer. Cell Res. (2016) 27:38-58. doi: 10.1038/cr.2016.154

49. Norelli M, Camisa B, Barbiera G, Falcone L, Purevdorj A, Genua M, et al. Monocyte-derived IL-1 and IL-6 are differentially required for cytokinerelease syndrome and neurotoxicity due to CAR T cells. Nat Med. (2018) 24:739-48. doi: 10.1038/s41591-018-0036-4

50. Giavridis T, van der Stegen SJC, Eyquem J, Hamieh M, Piersigilli A, Sadelain M. CAR T cell-induced cytokine release syndrome is mediated by macrophages and abated by IL-1 blockade. Nat Med. (2018) 24:7318. doi: 10.1038/s41591-018-0041-7

51. Hay KA, Hanafi LA, Li D, Gust J, Liles WC, Wurfel MM, et al. Kinetics and biomarkers of severe cytokine release syndrome after CD19 chimeric antigen receptor-modified T-cell therapy. Blood. (2017) 130:2295306. doi: 10.1182/blood-2017-06-793141

52. Wang Z, Han W. Biomarkers of cytokine release syndrome and neurotoxicity related to CAR-T cell therapy. Biomarker Res. (2018) 6:4. doi: 10.1186/s40364-018-0116-0

53. Maude SL, Frey N, Shaw PA, Aplenc R, Barrett DM, Bunin NJ, et al. Chimeric antigen receptor T cells for sustained remissions in leukemia. $N$ Engl J Med. (2014) 371:1507-17. doi: 10.1056/NEJMoa1407222

54. Barrett DM, Grupp SA, June CH. Chimeric antigen receptor- and TCRmodified $\mathrm{T}$ cells enter main street and wall street. J Immunol. (2015) 195:755-61. doi: 10.4049/jimmunol.1500751

55. Krenciute G, Prinzing BL, Yi Z, Wu MF, Liu H, Dotti G, et al. Transgenic expression of IL15 improves antiglioma activity of IL13Ralpha2-CAR T cells but results in antigen-loss variants. Cancer Immunol Res. (2017) 19(Suppl. 4):iv31. doi: 10.1093/neuonc/nox083.127

56. Seo H, Chen J, González-Avalos E, Samaniego-Castruita D, Das A, Wang $\mathrm{YH}$, et al. TOX and TOX2 transcription factors cooperate with NR4A transcription factors to impose CD8 ${ }^{+}$T cell exhaustion. Proc Natl Acad Sci. (2019) 116:12410-5. doi: 10.1073/pnas.1905675116
57. Chen J, López-Moyado IF, Seo H, Lio CJ, Hempleman LJ, Sekiya T, et al. NR4A transcription factors limit CAR $\mathrm{T}$ cell function in solid tumours. Nature. (2019) 567:530-4. doi: 10.1038/s41586-019-0985-x

58. Guedan S, Posey AD, Shaw C, Wing A, Da T, Patel PR, et al. Enhancing CAR T cell persistence through ICOS and 4-1BB costimulation. JCI Insight. (2018) 3:96976. doi: 10.1172/jci.insight.96976

59. Brodt P. Role of the microenvironment in liver metastasis: From pre- to prometastatic niches. Clin Cancer Res. (2016) 22:5971-82. doi: 10.1158/1078-0432.CCR-16-0460

60. Kasakovski D, Xu L, Li Y. T cell senescence and CAR-T cell exhaustion in hematological malignancies. J Hematol Oncol. (2018) 11:91. doi: 10.1186/s13045-018-0629-x

61. Newick K, Moon E, Albelda SM. Chimeric antigen receptor T-cell therapy for solid tumors. Mol Ther Oncol. (2016) 3:E191. doi: 10.1038/mto.2016.6

62. Zhong XS, Matsushita M, Plotkin J, Riviere I, Sadelain M. Chimeric antigen receptors combining $4-1 \mathrm{BB}$ and $\mathrm{CD} 28$ signaling domains augment PI 3 kinase/AKT/Bcl-X L activation and CD8 + T cell-mediated tumor eradication. Mol Ther. (2010) 18:413-20. doi: 10.1038/mt.2009.210

63. Hernandez I, Prasad V, Gellad WF. Total costs of chimeric antigen receptor T-cell immunotherapy. JAMA Oncol. (2018) 4:E1-3. doi: 10.1001/jamaoncol.2018.0977

64. Whittington MD, Ollendorf DA, Campbell JD. Accounting for all costs in the total cost of chimeric antigen receptor T-cell immunotherapy accounting for all costs in the total cost of chimeric antigen receptor T-cell immunotherapy letters. JAMA Oncol. (2018) 4:1784-5. doi: 10.1001/jamaoncol.2018.4625

65. Calmels B, Mfarrej B, Chabannon C. From clinical proof-of-concept to commercialization of CAR T cells. Drug Discov Today. (2018) 23:75862. doi: 10.1016/j.drudis.2018.01.024

66. Zhao WH, Liu J, Wang BY, Chen YX, Cao XM, Yang Y, et al. A phase 1, open-label study of LCAR-B38M, a chimeric antigen receptor $\mathrm{T}$ cell therapy directed against $\mathrm{B}$ cell maturation antigen, in patients with relapsed or refractory multiple myeloma. J Hematol Oncol. (2018) 11:141. doi: 10.1186/s13045-018-0681-6

67. Yang F, Zhang J, Zhang X, Tian M, Wang J, Kang L, et al. Delayed remission following sequential infusion of humanized CD19- and CD22-modified CAR-T cells in a patient with relapsed/refractory acute lymphoblastic leukemia and prior exposure to murine-derived CD19-directed CART cells. Onco Targets Ther. (2019) 12:2187-91. doi: 10.2147/OTT. S189103

68. Kosti P, Maher J, Arnold JN. Perspectives on chimeric antigen receptor T-cell immunotherapy for solid tumors. Front Immunol. (2018) 9:1104. doi: 10.3389/fimmu.2018.01104

69. Scott EM, Duffy MR, Freedman JD, Fisher KD, Seymour LW. Solid tumor immunotherapy with T cell engager-armed oncolytic viruses. Macromol Biosci. (2017) 18:1700187. doi: 10.1002/mabi.201700187

70. Weng J, Lai P, Qin L, Lai Y, Jiang Z, Luo C, et al. A novel generation 1928zT2 CAR $\mathrm{T}$ cells induce remission in extramedullary relapse of acute lymphoblastic leukemia. J Hematol Oncol. (2018) 11:25. doi: 10.1186/s13045-018-0572-X

71. Zhu YM, Wu Z, Tan YP, Du YY, Liu Z, Ou RM, et al. Anti-CD19 chimeric antigen receptor T-cell therapy for adult Philadelphia chromosomepositive acute lymphoblastic leukemia: two case reports. Medicine. (2016) 95:e5676. doi: 10.1097/MD.0000000000005676

72. Turtle CJ, Hanafi LA, Berger C, Gooley TA, Cherian S, Hudecek M, et al. CD19 CAR-T cells of defined CD4+:CD8+ composition in adult B cell ALL patients. J Clin Invest. (2016) 126:2123-38. doi: 10.1172/JCI85309

73. Wang CM, Wu ZQ, Wang Y, Guo YL, Dai HR, Wang XH, et al. Autologous $\mathrm{T}$ cells expressing CD30 chimeric antigen receptors for relapsed or refractory Hodgkin lymphoma: an open-label phase I trial. Clin Cancer Res. (2017) 23:1156-66. doi: 10.1158/1078-0432.CCR-16-1365

74. Kochenderfer JN, Dudley ME, Kassim SH, Somerville RP, Carpenter RO, Stetler-Stevenson M, et al. Chemotherapy-refractory diffuse large B-cell lymphoma and indolent B-cell malignancies can be effectively treated with autologous T cells expressing an anti-CD19 chimeric antigen receptor. J Clin Oncol. (2015) 33:540-9. doi: 10.1200/JCO.2014.56.2025

75. Porter DL, Hwang WT, Frey NV, Lacey SF, Shaw PA, Loren AW, et al. Chimeric antigen receptor $\mathrm{T}$ cells persist and induce sustained remissions 
in relapsed refractory chronic lymphocytic leukemia. Sci Transl Med. (2015) 7:303ra139. doi: 10.1126/scitranslmed.aac5415

76. Davila ML, Riviere I, Wang X, Bartido S, Park J, Curran K, et al. Efficacy and toxicity management of $19-28 \mathrm{z}$ CAR $\mathrm{T}$ cell therapy in B cell acute lymphoblastic leukemia. Sci Transl Med. (2014) 6:224ra225. doi: 10.1126/scitranslmed.3008226

77. Turtle CJ, Hanafi LA, Berger C, Hudecek M, Pender B, Robinson E, et al. Immunotherapy of non-Hodgkin's lymphoma with a defined ratio of $\mathrm{CD} 8^{+}$ and $\mathrm{CD}^{+}{ }^{+} \mathrm{CD} 19$-specific chimeric antigen receptor-modified T cells. Sci Translat Med. (2016) 8:355ra116. doi: 10.1126/scitranslmed.aaf8621

78. Wang Y, Zhang WY, Han QW, Liu Y, Dai HR, Guo YL, et al. Effective response and delayed toxicities of refractory advanced diffuse large B-cell lymphoma treated by $\mathrm{CD} 20$-directed chimeric antigen receptor-modified $\mathrm{T}$ cells. Clin Immunol. (2014) 155:160-75. doi: 10.1016/j.clim.2014.10.002

79. Fry TJ, Shah NN, Orentas RJ, Stetler-Stevenson M, Yuan CM, Ramakrishna $\mathrm{S}$, et al. CD22-targeted CAR T cells induce remission in B-ALL that is naive or resistant to CD19-targeted CAR immunotherapy. Nat Med. (2017) 24:20-8. doi: 10.1038/nm.4441

80. Ramos CA, Ballard B, Zhang H, Dakhova O, Gee AP, Mei Z, et al. Clinical and immunological responses after CD30-specific chimeric antigen receptor-redirected lymphocytes. J Clin Investig. (2017) 127:346271. doi: $10.1172 /$ JCI94306

81. Ritchie DS, Neeson PJ, Khot A, Peinert S, Tai T, Tainton K, et al. Persistence and efficacy of second generation CAR T cell against the LeY antigen in acute myeloid leukemia. Mol Ther. (2013) 21:2122-9. doi: 10.1038/mt.2013.154

82. Garber K. Driving T-cell immunotherapy to solid tumors. Nat Biotechnol. (2018) 36:215-9. doi: 10.1038/nbt.4090

83. Feng K, Guo Y, Dai H, Wang Y, Li X, Jia H, et al. Chimeric antigen receptormodified $\mathrm{T}$ cells for the immunotherapy of patients with EGFR-expressing advanced relapsed/refractory non-small cell lung cancer. Sci China Life Sci. (2016) 59:468-79. doi: 10.1007/s11427-016-5023-8

84. Louis CU, Savoldo B, Dotti G, Pule M, Yvon E, Myers GD, et al. Antitumor activity and long-term fate of chimeric antigen receptorpositive T cells in patients with neuroblastoma. Blood. (2011) 118:60506. doi: 10.1182/blood-2011-05-354449

85. Gargett T, Yu W, Dotti G, Yvon ES, Christo SN, Hayball JD, et al. GD2specific CAR $\mathrm{T}$ cells undergo potent activation and deletion following antigen encounter but can be protected from activation-induced cell death by PD-1 blockade. Mol Ther. (2016) 24:1135-49. doi: 10.1038/mt.2016.63

86. Brown CE, Badie B, Barish ME, Weng L, Ostberg JR, Chang WC, et al. Bioactivity and safety of IL13Ralpha2-redirected chimeric antigen receptor CD8+ T cells in patients with recurrent glioblastoma. Clin Cancer Res. (2015) 21:4062-72. doi: 10.1158/1078-0432.CCR-15-0428

87. Brown CE, Alizadeh D, Starr R, Weng L, Wagner JR, Naranjo A, et al. Regression of glioblastoma after chimeric antigen receptor T-cell therapy. $N$ Engl J Med. (2016) 375:2561-9. doi: 10.1056/NEJMoa1610497

88. Ahmed N, Brawley VS, Hegde M, Robertson C, Ghazi A, Gerken C, et al. Human epidermal growth factor receptor 2 (HER2)-specific chimeric antigen receptor-modified T cells for the immunotherapy of HER2-positive sarcoma. J Clin Oncol. (2015) 33:1688-96. doi: 10.1200/JCO.2014.58.0225

89. Lamers CH, Willemsen R, van Elzakker P, van Steenbergen-Langeveld S, Broertjes M, Oosterwijk-Wakka J, et al. Immune responses to transgene and retroviral vector in patients treated with ex vivo-engineered T cells. Blood. (2011) 117:72-82. doi: 10.1182/blood-2010-07-294520

90. Lamers CH, Sleijfer S, van Steenbergen S, van Elzakker P, van Krimpen B, Groot C, et al. Treatment of metastatic renal cell carcinoma with CAIX CARengineered T cells: Clinical evaluation and management of on-target toxicity. Mol Ther. (2013) 21:904-12. doi: 10.1038/mt.2013.17

91. Maus MV, Haas AR, Beatty GL, Albelda SM, Levine BL, Liu X, et al. T cells expressing chimeric antigen receptors can cause anaphylaxis in humans. Cancer Immunol Res. (2013) 1:26-31. doi: 10.1158/2326-6066.CIR-13-0006

92. Beatty GL, Haas AR, Maus MV, Torigian DA, Soulen MC, Plesa G, et al. Mesothelin-specific chimeric antigen receptor mRNA-engineered T cells induce anti-tumor activity in solid malignancies. Cancer Immunol Res. (2014) 2:112-20. doi: 10.1158/2326-6066.CIR-13-0170

93. You F, Jiang L, Zhang B, Lu Q, Zhou Q, Liao X, et al. Phase 1 clinical trial demonstrated that MUC1 positive metastatic seminal vesicle cancer can be effectively eradicated by modified anti-MUC1 chimeric antigen receptor transduced T cells. Sci China Life Sci. (2016) 59:38697. doi: 10.1007/s11427-016-5024-7

94. Katz SC, Burga RA, McCormack E, Wang LJ, Mooring W, Point GR, et al. Phase I hepatic immunotherapy for metastases study of intra-arterial chimeric antigen receptor-modified T-cell therapy for CEA+ liver metastases. Clin Cancer Res. (2015) 21:3149-59. doi: 10.1158/1078-0432.CCR-14-1421

95. Ali SA, Shi V, Maric I, Wang M, Stroncek DF, Rose JJ, et al. $\mathrm{T}$ cells expressing an anti-B-cell maturation antigen chimeric antigen receptor cause remissions of multiple myeloma. Blood. (2016) 128:1688700. doi: 10.1182/blood-2016-04-711903

96. Tchou J, Zhao Y, Levine BL, Zhang PJ, Davis MM, Melenhorst JJ, et al. Safety and efficacy of intratumoral injections of chimeric antigen receptor (CAR) T cells in metastatic breast cancer. Cancer Immunol Res. (2017) 5:1152-61. doi: 10.1158/2326-6066.CIR-17-0189

97. Junghans RP, Ma Q, Rathore R, Gomes EM, Bais AJ, Lo AS, et al. Phase I trial of anti-PSMA designer CAR-T cells in prostate cancer: Possible role for interacting interleukin 2-T cell pharmacodynamics as a determinant of clinical response. Prostate. (2016) 76:1257-70. doi: 10.1002/pros.23214

98. Hege KM, Bergsland EK, Fisher GA, Nemunaitis JJ, Warren RS, McArthur JG, et al. Safety, tumor trafficking and immunogenicity of chimeric antigen receptor (CAR)-T cells specific for TAG-72 in colorectal cancer. $J$ Immunother Cancer. (2017) 5:22. doi: 10.1186/s40425-017-0222-9

99. Smith TT, Moffett HF, Stephan SB, Opel CF, Dumigan AG, Jiang X, et al. Biopolymers codelivering engineered $\mathrm{T}$ cells and STING agonists can eliminate heterogeneous tumors. J Clin Investig. (2017) 127:217691. doi: $10.1172 / J C I 87624$

100. Kueberuwa G, Kalaitsidou M, Cheadle E, Hawkins RE, Gilham DE. CD19 CAR T-cells expressing IL-12 eradicate lymphoma in fully lymphoreplete mice through induction of host immunity. Mol Ther Oncol. (2018) 8:4151. doi: $10.1016 /$ j.omto.2017.12.003

101. Zhang N, Chen J, Ferraro GB, Wu L, Datta M, Jain RK, et al. Anti-VEGF treatment improves neurological function in tumors of the nervous system. Exp Neurol. (2017) 299(Pt B):326-33. doi: 10.1016/j.expneurol.2017.09.008

102. Xu Y, Yang Z, Horan LH, Zhang P, Liu L, Zimdahl B, et al. A novel antibody-TCR (AbTCR) platform combines Fab-based antigen recognition with gamma/delta-TCR signaling to facilitate T-cell cytotoxicity with low cytokine release. Cell Discov. (2018) 4:62. doi: 10.1038/s41421-018-0066-6

103. Blüthmann H, Kisielow P, Uematsu Y, Malissen M, Krimpenfort P, Berns A, et al. T-cell-specific deletion of T-cell receptor transgenes allows functional rearrangement of endogenous $\alpha$ - and $\beta$-genes. Nature. (1988) 334:1569. doi: $10.1038 / 334156 \mathrm{a} 0$

104. Rapoport AP, Stadtmauer EA, Binder-Scholl GK, Goloubeva O, Vogl DT, Lacey SF, et al. NY-ESO-1-specific TCR-engineered T cells mediate sustained antigen-specific antitumor effects in myeloma. Nat Med. (2015) 21:91421. doi: $10.1038 / \mathrm{nm} .3910$

105. Kavunja HW, Lang S, Sungsuwan S, Yin Z, Huang X. Delivery of foreign cytotoxic T lymphocyte epitopes to tumor tissues for effective antitumor immunotherapy against pre-established solid tumors in mice. Cancer Immunol Immunother. (2017) 66:451-60. doi: 10.1007/s00262-016-1948-9

106. Tawara I, Kageyama S, Miyahara Y, Fujiwara H, Nishida T, Akatsuka Y, et al. Safety and persistence of WT1-specific T-cell receptor gene-transduced lymphocytes in patients with AML and MDS. Blood. (2017) 130:198594. doi: 10.1182/blood-2017-06-791202

107. Johnson LA, Morgan RA, Dudley ME, Cassard L, Yang JC, Hughes MS, et al. Gene therapy with human and mouse T-cell receptors mediates cancer regression and targets normal tissues expressing cognate antigen. Blood. (2009) 114:535-46. doi: 10.1182/blood-2009-03-211714

108. Parkhurst MR, Yang JC, Langan RC, Dudley ME, Nathan DA, Feldman SA, et al. T cells targeting carcinoembryonic antigen can mediate regression of metastatic colorectal cancer but induce severe transient colitis. Mol Ther. (2011) 19:620-6. doi: 10.1038/mt.2010.272

109. Robbins PF, Morgan RA, Feldman SA, Yang JC, Sherry RM, Dudley ME, et al. Tumor regression in patients with metastatic synovial cell sarcoma and melanoma using genetically engineered lymphocytes reactive with NY-ESO1. J Clin Oncol. (2011) 29:917-24. doi: 10.1200/JCO.2010.32.2537

110. Linette GP, Stadtmauer EA, Maus MV, Rapoport AP, Levine BL, Emery L, et al. Cardiovascular toxicity and titin cross-reactivity of 
affinity-enhanced T cells in myeloma and melanoma. Blood. (2013) 122:86371. doi: 10.1182/blood-2013-03-490565

111. Kageyama S, Ikeda H, Miyahara Y, Imai N, Ishihara M, Saito K, et al. Adoptive transfer of MAGE-A4 T-cell receptor gene-transduced lymphocytes in patients with recurrent esophageal cancer. Clin Cancer Res. (2015) 21:2268-77. doi: 10.1158/1078-0432.CCR-14-1559

112. Peng PD, Cohen CJ, Yang S, Hsu C, Jones S, Zhao Y, et al. Efficient nonviral Sleeping Beauty transposon-based TCR gene transfer to peripheral blood lymphocytes confers antigen-specific antitumor reactivity. Gene Ther. (2009) 16:1042-9. doi: 10.1038/gt.2009.54
Conflict of Interest: The authors declare that the research was conducted in the absence of any commercial or financial relationships that could be construed as a potential conflict of interest.

Copyright $\odot 2019$ Zhao and Cao. This is an open-access article distributed under the terms of the Creative Commons Attribution License (CC BY). The use, distribution or reproduction in other forums is permitted, provided the original author(s) and the copyright owner(s) are credited and that the original publication in this journal is cited, in accordance with accepted academic practice. No use, distribution or reproduction is permitted which does not comply with these terms. 